Chapman University

Chapman University Digital Commons

ESI Working Papers

Economic Science Institute

10-29-2018

\title{
Agglomeration and the Extent of the Market: An Experimental Investigation into Spatially Coordinated Exchange
}

Jordan Adamson

Chapman University, jadamson@chapman.edu

Follow this and additional works at: https://digitalcommons.chapman.edu/esi_working_papers

Part of the Econometrics Commons, Economic Theory Commons, and the Other Economics Commons

\section{Recommended Citation}

Adamson, J. (2018). Agglomeration and the extent of the market: An experimental investigation into spatially coordinated exchange. ESI Working Paper 18-12. Retrieved from https://digitalcommons.chapman.edu/esi_working_papers/250

This Article is brought to you for free and open access by the Economic Science Institute at Chapman University Digital Commons. It has been accepted for inclusion in ESI Working Papers by an authorized administrator of Chapman University Digital Commons. For more information, please contactlaughtin@chapman.edu. 


\title{
Agglomeration and the Extent of the Market: An Experimental Investigation into Spatially Coordinated Exchange
}

\author{
Comments \\ Working Paper 18-12
}




\title{
Agglomeration and the Extent of the Market: An Experimental Investigation into Spatially Coordinated Exchange
}

\author{
Jordan Adamson *†
}

Original Draft: October 15, 2017

This Draft: December 27, 2018

\begin{abstract}
How and why do agglomerations emerge? While economic historians emphasize trade and economic geographers emphasize variety, we still do not understand the role of coordination. I fill this gap by creating a pure-exchange location coordination game and then testing the model in a laboratory experiment. Although there is a huge strategy space and multiple equilibria, the model predicts that marketplaces can emerge as a resilient solution to a highly complex problem of coordinating a multi-coincidence of wants and locations. In the experiment, I find individuals tend to coalesce purely to coordinate exchange, that individuals re-agglomerate at the same locations, and that these location choices aggregate to create a Zipf population distribution. I also test two agglomeration mechanisms by exogenously varying the number of different goods in the economy and whether traders residences are land-tied or not. I find that there is more agglomeration in economies with a larger variety of goods, that being land-tied reduces agglomeration, and that being land-tied magnifies the effect of variety.
\end{abstract}

Keywords: Spatial Coordination, Agglomeration, Pure-Exchange

JEL Classification: R12, C92, F19

\footnotetext{
* Affiliation: Smith Institute for Political Economy and Philosophy, Chapman University. Email: Jadamson@chapman.edu. Homepage: https://sites.google.com/view/jordan-adamson.

†Thanks to Erik Kimbrough, David Rojo Arjona, Bart Wilson, Patrick Warren, Nat Wilcox, Andrea Matranga, Avner Seror, Anne Anders, and Dustin Tracy for comments and suggestions. Thanks also to participants at the Global Conference for Economic Geography 2018, the MIT \& YSI Conference on Economic Geography and Complexity 2018, and the Clemson Workshop on Public Economics 2018. Thanks to Amazon Web Server for providing funds for part of this research.
} 
Smiths, carpenters, wheelwrights, and ploughwrights, masons, and bricklayers, tanners, shoemakers, and tailors are people whose service the farmer has frequent occasion for. Such artificers, too, stand occasionally in need of the assistance of one another; and as their residence is not, like that of the farmer, necessarily tied down to a precise spot, they naturally settle in the neighbourhood of one another, and thus form a small town or village... The town is a continual fair or market, to which the inhabitants of the country resort in order to exchange...

- Adam Smith Wealth of Nations, Book III

\section{Introduction}

Cities and marketplaces are central to economic development, but our understanding of how they form and what functions they perform is still very partial. While many scholars of early cities emphasize the role of trade, it is difficult to empirically establish causality. ${ }^{1}$ On the other hand, scholars of agglomeration who use satellite evidence from the modern era are divided on the importance of trade: Henderson et al. (2018) argues agriculture is the fundamental force, while Desmet, Nagy, and Rossi-Hansberg (2018) argue for an important interaction between trade with migration. But since we lack data allowing identification of the micro-mechanisms (Combes, Duranton, and Gobillon 2011; Gibbons and Overman 2012), I use the experimental method to generate agglomerations from individual choices. But to test the mechanisms in the lab, I first modify the standard model of agglomeration.

I develop a pure-exchange location-coordination game, based on historical narratives and Smith's (1776) theory of agglomeration. In the model, geographically dispersed individuals want to get together to obtain a variety of goods from others but incur costs of doing so. I formalize this by extending the model of Fudenberg and Ellison (2003) and Anderson, Ellison, and Fudenberg (2010) to have multiple individuals trading multiple goods at multiple locations. Although the game has a huge strategy space, it allows me to focus on the effects of trading new goods (emphasized by Christaller 1933; Boulding 1964; Romer 1994). It does so by separating preference parameters from the fixed costs of production, which Neary (2001) argued are confounded in the standard model. The model also allows me to separate the effect of residences being land-tied, also noted by Krugman (1991) of agriculture, from other factors like constant-returns technologies and transportation costs. In my game, agglomerations can only emerge through individuals' desires to spatially coordinate exchange and not from typical factors like externalities, increasing returns, or imperfect competition. ${ }^{2}$

This setup provides testable hypothesis about how and why agglomerations emerge. Although the game has multiple equilibria, when individuals agglomerate they still reap the gains from trade when others stochastically deviate or the environment changes, and this means evolutionary forces should select for them. Furthermore, agglomerations serve as focal points in this coordination game, which suggests that agglomerations will re-emerge at the same location after shocks. The game also allows me to isolate and analyze two of the central forces in agglomeration formation: the variety of goods obtained from

\footnotetext{
${ }^{1}$ See Appendix A.1 for a review of this historical literature.

${ }^{2}$ For example, the 2009 World Bank Development describes New York and Paris in this way. There is a vast literature that builds on the model developed by Krugman (1991), with origins in Marshall (1920), on the emergence of cities based on attributes of production (Krugman 1996; Fujita, Krugman, and Venables 2001; Tabuchi and Thisse 2011; Fujita and Thisse 2013a; De Palma and Papageorgiou 2017).
} 
exchange and whether or not individuals are tied to the land. Although there are multiple equilibria, I predict that increasing the variety of goods in the economy creates larger gains from trade and more agglomeration. I also argue that releasing individuals from the land should increase agglomeration, but this changes the game into a dynamic problem that is too complex to explicitly solve for all equilibria. So because of the multiple equilibria, as well as the complicated comparative statics, I test the implications of my model with a laboratory experiment.

I perform a laboratory experiment that generates multiple realizations of the entire agglomerating process, and this creates clear counterfactuals from weak econometric assumptions. Specifically, I initially distribute individuals evenly over a featureless rectangular grid and then observe how the geographic distribution of individuals evolves from period to period as individuals change locations to trade. ${ }^{3}$ Different treatments test the variety and land-tied mechanisms by exogenously varying the number of different goods in the economy and whether traders are land-tied or not. My experiment builds on Kimbrough, Smith, and Wilson (2008), Kimbrough and Wilson (2011), and Banerjee, Kwasnica, and Shortle (2012) and it allows me to clearly identify agglomeration when it occurs and to isolate the causal mechanisms.

The results show that geographically dispersed traders spontaneously coalesce to reap the gains from trade. A marketplace emerges in both senses of the word 'geographic coordinate': a physical point on a map and a focal point coordinating traders. While central marketplaces are not the equilibria with the highest average payoffs (as often emphasized in theory), groups that form central marketplaces in the experiment obtain higher payoffs than those that do not. Furthermore, the results of the different treatments also show that there is more agglomeration in economies with a larger variety of goods, being land-tied reduces agglomeration, but being land-tied magnifies the effect of variety. Finally, I show the sum of individual location choices aggregate to create a Zipf population distribution, which shows coordinated-exchange is a consistent explanation for both the historical narrative and the macro statistics. As a whole, these experiments reinforce Smith's narrative of agglomeration and furthers our understanding of the mechanisms.

\section{Theory}

I examine a two-stage location coordination game where individuals make location choices in the first stage choice based on the benefits from trade in the second stage. In the model of Fudenberg and Ellison (2003), a large number of buyers and sellers simultaneously choose one of two locations in the first stage based on second stage payoffs (which are general to any second stage game). In the first stage of my game, a smaller number of individuals simultaneously choose where to locate on a two dimensional grid and which good to bring. Trading multiple goods is an especially important innovation that highlights the role of variety in motivating exchange - a point I make concretely by assuming Constant Elasticity of Substitution (CES) preferences. ${ }^{4}$ In the second stage of my game, individuals trade their good with other individuals at the same location under competitive-market conditions. To calculate the equilibria, I first solve for the second stage consumption payoffs after good and location decisions have been made, and then endogenize the decisions of where to bring which goods.

\footnotetext{
${ }^{3}$ As such, I create a virtual petri dish to observe agglomeration. This mimics the setup of Christaller (1933), who modelled central places emerging on a blank slate, and complements modern geocell analysis.

${ }^{4}$ Note CES preferences mean any new goods are equally complementary to any goods already being consumed.
} 


\subsection{Stage 2, Pure Exchange}

Each individual $i$ maximizes an identical CES utility function subject to a budget constraint $M_{i}$ to obtain a payoff of $U_{i}^{2}$ (superscript denotes the stage). Let $X_{i, g}$ represent the quantity that $i$ consumes of good $g$, $P_{g}$ as the price, $n$ as the number of goods, and $\rho \in(0,1]$ as the substitute/complements parameter. Where

$$
\max _{X_{i, 1}, \ldots, X_{i, g}} \quad U_{i}^{2}=\left[\sum_{g=1}^{n} X_{i, g}^{\rho}\right]^{1 / \rho} \quad \text { s.t. } \quad M_{i}=\sum_{g=1}^{n} P_{g} X_{i, g}
$$

yields individual consumption and payoffs

$$
\begin{aligned}
X_{i, g}^{*} & =M_{i} P_{g}^{\frac{1}{\rho-1}} / \sum_{g^{\prime}} P_{g^{\prime}}^{\frac{\rho}{\rho-1}} \\
U_{i}^{2} & =M_{i}\left[\sum_{g=1}^{n} P_{g}^{\frac{\rho}{\rho-1}}\right]^{\frac{1-\rho}{\rho}}
\end{aligned}
$$

In a pure-endowment economy, there is a fixed total quantity $\overline{\Omega_{g}}$ of each good $g$. Under competitiveequilibrium conditions $\overline{\Omega_{g}}=\sum_{i} X_{i, g}^{*}$ imply the price ratio for goods $g$ and $g^{\prime}$ is $\left(P_{g} / P_{g^{\prime}}\right)^{\frac{1}{\rho-1}}=\overline{\Omega_{g}} / \overline{\Omega_{g^{\prime}}}$. An individual endowed with a quantity $\Omega_{g}$ of good $g^{\prime}$ earns an income $M_{i}=P_{g^{\prime}} \Omega_{g^{\prime}}$ which leads to a payoff

$$
U_{i}^{2}=\Omega_{g^{\prime}}\left[\sum_{g=1}^{n}\left(\frac{\overline{\Omega_{g}}}{\overline{\Omega_{g^{\prime}}}}\right)^{\rho}\right]^{\frac{1-\rho}{\rho}}
$$

\subsection{Stage 1, Coordinating Who brings What Where}

Each individual $i$ is has a home location $\triangle_{i}$ on a grid $S=\left\{\left(x_{1}, y_{1}\right), \ldots,\left(x_{L}, y_{L}\right)\right\}$. In the baseline model, this home location is fixed. Individuals choose to bring an endowment $\Omega_{i} \in\left\{\Omega_{1}, \ldots, \Omega_{n}\right\}$ to a location $\ell_{i} \in S$ to earn payoffs according to equation 2. But individuals lose part of their endowment when they move; i.e person $i$ has a transportation cost $c\left(\triangle_{i}, \ell_{i}\right)$ to move from his current location $\triangle_{i}$ to location $\ell_{i}$. Since all endowments that are lost in getting to a location affect the equilibrium exchange rates, equation 2 refers to endowments net-of-transportation costs. Formally, denote $\overline{\Omega_{g}}\left(\ell_{i}\right)-\overline{c_{g}}\left(\ell_{i}\right)$ as the sum amount of $\Omega_{g}$ at $\ell_{i}$ that remains after individuals lost a total of $\overline{c_{g}}\left(\ell_{i}\right)$ along the way. Thus the utility achieved by individual $i$ in the first stage from choosing to bring $\Omega_{i}$ to $\ell_{i}$ is

$$
U_{i}^{1}\left(\ell_{i}, \Omega_{i}\right)=\left[\Omega_{i}-c\left(\triangle_{i}, \ell_{i}\right)\right]\left[\sum_{g=1}^{n}\left(\frac{\overline{\Omega_{g}}\left(\ell_{i}\right)-\overline{c_{g}}\left(\ell_{i}\right)}{\overline{\Omega_{i}}\left(\ell_{i}\right)-\overline{c_{i}}\left(\ell_{i}\right)}\right)^{\rho}\right]^{\frac{1-\rho}{\rho}}
$$

Equation 3 creates the following four points of intuition. 1) If I bring more of a good then my payoffs will be higher. 2) If others bring more of the same good as me then my payoffs will be lower. 3) If others bring a larger variety of different goods then my payoff will be higher. 4) The exact magnitude of these relations depends on the complementarity of the goods, i.e. there is no gain in agglomerating to obtain perfect substitutes. ${ }^{5}$ So individuals are coordinating locations and anti-coordinating goods. But equation

\footnotetext{
${ }^{5}$ Two dimensions were chosen rather than one because one dimensional models often have results that do not generalize
} 
3 also shows each individual's payoffs are highly contingent on the environment: everyones locations, costs, endowments, and preferences. This means I have to focus on one specific game because too many computations are required to explore multiple environments. A game with $n$ goods, $L$ locations, and $I$ individuals creates a strategy space of $(n \times L)^{I}$ different choice combinations to evaluate in finding all of the pure-strategy equilibria for each environment. So I focus on the smallest number of goods that allow for comparative statics on variety and the maximum number of individuals and locations that were computationally feasible to analyze.

There are $I=6$ individuals with identical $\operatorname{CES}(\rho=.5)$ utility functions on a $5 \times 3$ grid of locations. There is a 2 unit Manhattan distance cost for moving from home to destination locations - i.e. an individual with $\triangle_{i}=\left(x_{1}, y_{1}\right)$ locating at $\ell_{i}=\left(x_{2}, y_{2}\right)$ incurs cost $c\left(\triangle_{i}, \ell_{i}\right)=2\left(\left|x_{1}-x_{2}\right|+\left|y_{1}-y_{2}\right|\right)$. Each individual is endowed with 12 units of whatever good they choose and they can move to any location on the grid. Figure 1 shows the initial locations with of arbitrary endowments. The left subfigure shows the game when each individual can choose from $\{12 \varpi, 12 \bullet\}$ and the right subfigure shows the game when each individual can choose from $\{12 \backsim, 12 \bullet, 12 \triangleleft\}$.

Figure 1: Initial Spatial Distributions
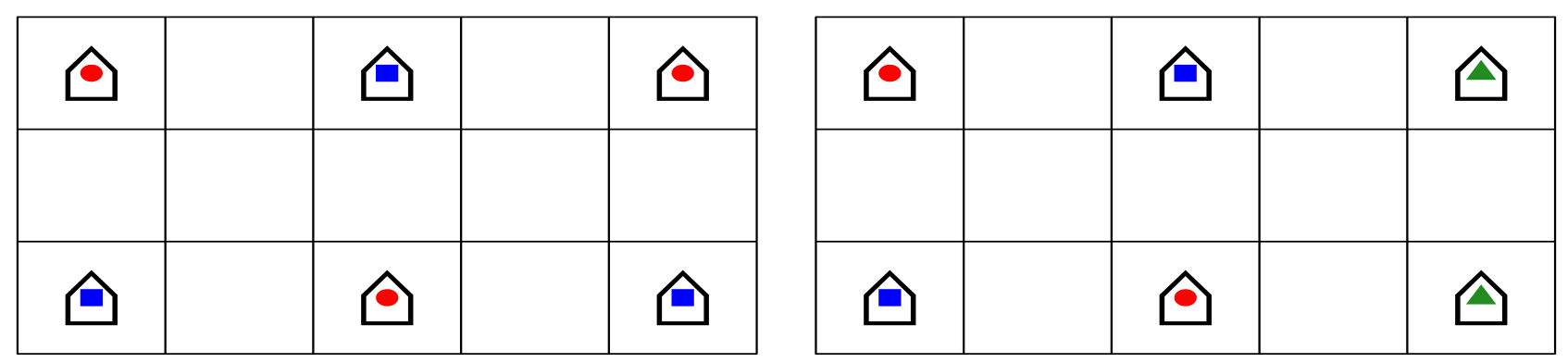

I numerically compute all of the pure-strategy Nash-equilibria for this game. My computations show there are a large number of equilibria, but many are similar (isomorphic). So I adopt the "Boltzmann Principle" from statistical entropy and measure microstates, macrostates, and the number of microstates per macrostate. Here, "microstates" are equilibria describing exactly who does what where, and a "macrostate" describes multiple microstates that are the same along many dimensions (i.e. isomorphic equilibria). Specifically, a macrostate describes the number of locations covered and the number of individuals who bring each good. For example, consider the macrostate where 3 individuals bring and 3 individuals bring $\bullet$ to a single location. This macrostate is consistent with individuals $1,2,3$ bringing and individuals 4,5,6 bringing $\bullet$ to location $a$. But this macrostate is also consistent with the microstate where those individuals bring those goods to another location $b$, and the multiple microstates where different individuals are bringing those goods. While analyzing macrostates instead of microstates discards information, it could potentially simplify the analysis a great deal. Table 1 summarizes that game with the number of potential microstates (the strategy space), the number of microstates and the mean number of microstates per macrostate.

(see Irmen and Thisse 1998 for example). 
Table 1: Game Summary

\begin{tabular}{lrrr}
\hline \hline & Strategy Space & \# Microstates & \# Microstates / Macrostate \\
\hline 2 Goods & 729000000 & 3784 & 252 \\
3 Goods & 8303765625 & 6498 & 224 \\
\hline
\end{tabular}

I formally define a "central marketplace" as the macrostate where all traders are located at the same location. This macrostate differs from the many other macrostates where trade is decentralized. For example, the payoff maximizing macrostate has many microstates where the closest individuals each bring one of the goods (i.e. three pairs in the 2 good environment or two triples in the 3 good environment). But although the central marketplace has very few microstates (i.e. is low-entropy), I show why evolutionary forces might select for it.

\subsection{Equilibria Payoffs and Resilience}

I show how central marketplaces emerge to allow traders to be coordinated in a very complex environment. I do this by merging evolutionary economic geography (Martin and Sunley 2007; Boschma and Martin 2010; Martin and Sunley 2012; Kogler 2015; Boschma and Frenken 2018) with the evolutionary game theory. In particular, I build on (Crawford and Haller 1990; Crawford 1991; Ellison 2000) by using the size of the basin of attraction as an equilibrium selection criterion. In particular, I use a notion of global (rather than local) stability which illustrates how "resilient" central marketplaces are.

I say an equilibrium is resilient if no individual wants to deviate from equilibrium under the belief that other individuals are deviating with large probability. These beliefs about deviations can be real (when other individuals use a mixed strategy) or imaginary (when others are simply assumed to have a trembling hand). The important point is that when an individual believes others make choices stochastically, some equilibria will be eliminated due to the lower expected payoffs that stem from the risk of miscoordination.

I show how resilient each equilibrium is by numerically computing expected utilities for different deviation magnitudes and eliminate equilibria from the pool when any individual is no-longer best responding. Formally, the expected utility for an individual $i$ is

$$
E\left[U_{i}^{1}\left(\ell_{i}, \Omega_{i}\right) \mid\left\{\left(\sigma_{\Omega,-i}+\varepsilon_{\sigma,-i}, \sigma_{\ell,-i}+\varepsilon_{\Omega,-i}\right)\right\}_{-i}\right]
$$

where $\left(\sigma_{\Omega,-i}, \sigma_{\ell,-i}\right)$ are vectors that specify the probability of individual $-i$ choosing the equilibrium $\left(\Omega_{-i}, \ell_{-i}\right)$, and $\left(\varepsilon_{\Omega,-i}, \varepsilon_{\ell,-i}\right)$ are vectors that specify the probability of deviating from equilibrium. ${ }^{6}$ In my computations, I scale the deviations from equilibrium to be in percentage terms so that a single parameter $e \in[0,1]$ is used to calculate the degree of strategic resilience. Specifically, for $L$ locations, there is $1-e(L-1) / L$ probability of choosing the equilibrium location and $e / L$ probability of choosing each other location. Likewise, for $n$ goods, there is $1-e(n-1) / n$ probability of choosing the equilibrium endowment and $e / n$ probability of choosing each other endowment. So $e=0$ specifies the pure strategy

${ }^{6}$ I use numerical computations to estimate expected utility. Specifically, I take the average of 1000 utility calculations for each individual $i$, where each calculation draws $\Omega_{-i} \sim \operatorname{Multinoulli}\left(\sigma_{\Omega,-i}+\varepsilon_{\Omega,-i}\right)$ and $\ell_{-i} \sim \operatorname{Multinoulli}\left(\sigma_{\ell,-i}+\varepsilon_{\ell,-i}\right) \forall-i$. 
equilibrium and $e=1$ specifies all actions are choosen with equal probability.

Figure 2 summarizes the distribution of average payoffs and strategic resilience for each equilibrium. The histograms show the marginal distributions of all microstate equilibria, and the scatterplot shows the averages for each macrostate. Most macrostates are on the left-side of the plot and are not resilient, including the payoff maximizing macrostate. This is because if you still show up at the right place with the right good and the other one or two players go to the wrong location or bring the wrong good, then you end up with a low payoff. On the other hand, central marketplaces are the most resilient macrostate. They are the bottom-most right-most macrostate in each plot, showing lower payoffs under strategic certainty but remain mutual best-responses under large deviations. This is because if you show up at the right place with the right good, you still earn a high payoff unless a large number of individuals go elsewhere or systematically bring the wrong goods.

Figure 2: Equilibrium Payoffs and Strategic Resilience

(a) 2 Goods

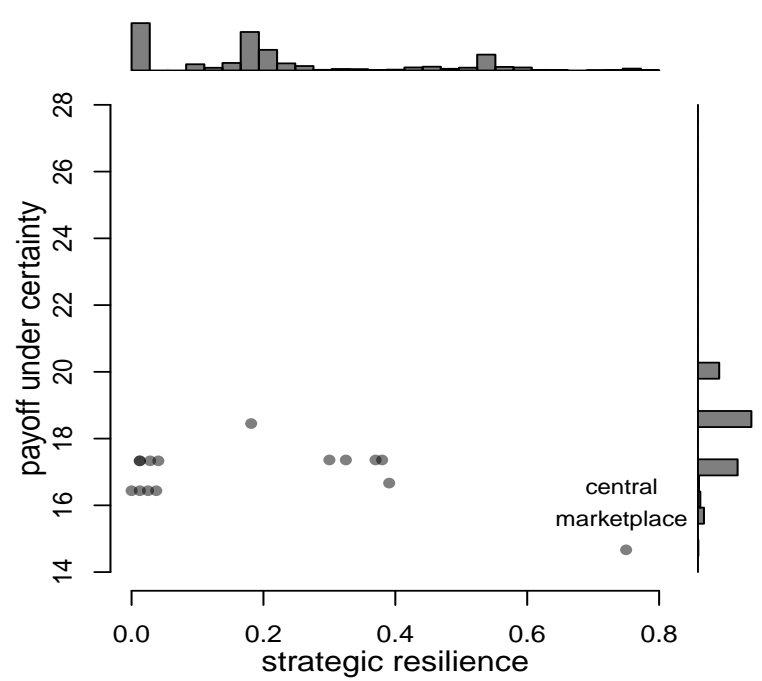

(b) 3 Goods

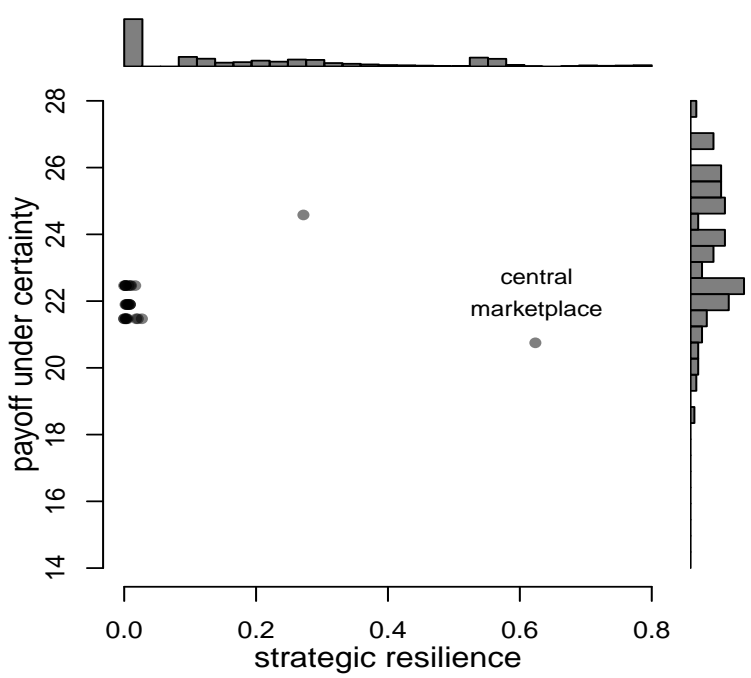

*scatterplots show macrostate averages, histograms show microstate marginal distributions

I use stochastic evolutionary game theory for equilibrium selection. If strategies are made stochastically, then an equilibrium with a larger basin of attraction is more likely to catch strategic mutations and a population is more likely to evolve towards it (Sandholm 2010). Since more resilient equilibria have a larger basin of attraction they are more likely to be selected. Thus the theory predicts

\section{Hypothesis 1: Central marketplaces are more likely to emerge.}

In particular, a central marketplace at the central cell is the most resilient. ${ }^{7}$ But I also show, using the theory of focal points (Schelling 2006; Mehta, Starmer, and Sugden 1994; Kramarz 1996; Isoni et al. 2013) to explain why agglomerations re-emerge at the same locations after shocks, even if not at the most resilient equilibrium. Building on the formal definition of dynamic focal points by Casajus (2001), central marketplaces are equilibria that are more likely to arise through the history of play and frame any

\footnotetext{
${ }^{7}$ This is because at least one individual at a corner of the grid will recieve lower payoffs if the agglomeration was elsewhere.
} 
stage-game currently being played. That historical frame should create a tendency towards agglomerating at the same locations, even after being physically reset. This prediction is noteworthy because it is well documented that cities are resilient, by Davis and Weinstein (2002) for example, but 'memory' is not predicted by the standard model (Martin and Sunley 2012). ${ }^{8}$ Thus the second hypotheses generated is

\section{Hypothesis 2: Once emerged, a central marketplace will re-emerge at the same location after shocks.}

There is a theoretical cost associate with this resilience, as welfare is given up in comparison to other states under strategic certainty. But this cost declines with the number of goods because payoffs at the central marketplace increase with the number of goods. This is because more new goods $\Rightarrow$ more gains from trade $\Rightarrow$ more benefits to agglomerating.

\subsection{The Effect of New Goods}

The variety of goods affects how steep the incentives are to agglomerate. Since there are still a large number of macrostates, I isolate and analyze the phenomena of interest: the incentives for a dispersed population of traders to coalesce towards a single agglomeration. The intuition for this argument is found by comparing an individuals' utility alone (consuming their endowment) to an individuals utility at the central agglomeration (trading for smaller amounts of more different goods). While the CES case is shown in Appendix Section A.2, the following illustration, where individuals always trade for an equal amount of the other goods available, makes the point. In a world with 3 goods, the incentive to agglomerate is

$$
U(1 / 3,1 / 3,1 / 3)-U(1,0,0)
$$

In a world with 2 goods, the incentive to agglomerate is

$$
U(1 / 2,1 / 2,0)-U(1,0,0)
$$

and the change in the agglomeration incentive is

$$
U(1 / 3,1 / 3,1 / 3)-U(1 / 2,1 / 2,0)
$$

The incentive to agglomerate is $\Delta U / \Delta n$ because when there are more new goods to be traded, there are more gains at a central marketplace. The CES complements parameter is also important because when the goods are more complementary the locations are more strategic-complementary. This also incentivizes agglomeration because the extensive-marginal utility is larger. But Smith (1776) did not emphasize preferences, he emphasized a large variety of agglomerators: Smiths, carpenters, wheelwrights, and ploughwrights, masons, and bricklayers, tanners, shoemakers, and tailors. For a large set of unobservable preferences, the incentive to agglomerate is determined by an observable number of new goods that can be obtained at a central marketplace. Figure 2 shows that new goods make coordination more desireable, with bigger increases for central marketplaces. Table 2 shows that distribution of microstates also changes, with more of the microstates describing individuals choosing to be less disperesed over different locations. The gains from trade shift the distribution of equilibria to be more spatially concentrated.

\footnotetext{
${ }^{8}$ Resilience is different than persistence, which is also predicted by model and much of the literature (i.e. Litina 2016; Allen and Donaldson 2018). Resilience results because coordinated agglomerations are stable for reasons that are assumed away in competitive agglomerations - i.e. individuals not being indifferent across space (Glaeser 2007) or having exogenously fixed locations (Hotelling 1929).
} 
Table 2: Number of Microstates by Spatial Coverage

\begin{tabular}{lrr}
\hline \hline & 2 Goods & 3 Goods \\
\hline 1 Locations Covered & 12 & 342 \\
2 Locations Covered & 580 & 5724 \\
3 Locations Covered & 3160 & 432 \\
4 Locations Covered & 32 & 0 \\
\hline
\end{tabular}

A larger number of goods in the economy also leads to a larger strategy space, a larger number of equilibria, and possibly more strategic uncertainty. Figure 2 shows that the central marketplace for 3 goods is less resilient in absolute value compared to the central marketplace for 2 goods. However, compared to distribution of other equilibria in a given environment, the central marketplace is more of a resilience outlier with the 3 goods compared to the 2 goods. In accordance with Hypothesis 1, this relative increase in resilience would further incentivize central marketplaces. Thus variety both increases the payoffs from agglomerating and increases the evolutionary pressure towards central marketplaces. ${ }^{9}$ This leads to the following prediction

Hypothesis 3: A larger variety of goods in the economy will lead to more agglomeration.

\subsection{Individuals Not Land-Tied}

In the baseline case discussed in the theory so far, individuals have home locations that are tied to a particular location and must choose where to locate and what to bring for trade. While this is a feature of many agricultural communities, many people are not farmers tied to the land. And since the predictions are derived based on the gains from trade, Hypothesis 3 is plausibly general to settings where individuals are not land-tied. But being land tied could also have it's own direct effect. When individuals are not land-tied the game becomes dynamic and creates two major differences. First, the cost of movement decreases so the game becomes less analogous to a battle of the sexes game and more analogous to a pure-coordination game. Second, there is a much larger strategy space and more strategic uncertainty. Based on the theoretical principles I've stated in Sections 2.4 and 2.3, this should lead to more agglomeration. The central marketplace could be more likely to emerge because it is resilient to changes in the home-locations of traders, and the benefits from going there are larger. ${ }^{10}$ Smith (1776) states that when their residence is not, like that of the farmer, necessarily tied down to a precise spot, they naturally settle in the neighbourhood of one another. But since the strategy space is too large to compute additional residence choices, the following hypotheses are stated without explicit derivation.

Hypothesis 3 (Strong Form): A larger variety of goods in the economy will lead to more agglomeration, even when individuals are not land-tied.

Hypothesis 4: Not being land-tied will lead to more agglomeration.

According to Smith (1776): the town is a continual fair or market resulting from the accumulation of a variety of traders who are not land-tied. In my game, trade alone is sufficient for agglomeration and

\footnotetext{
${ }^{9}$ An extreme example of the phenomena is when there are as many goods as players: then the central marketplace would have higher payoffs, a larger strategy space, a relatively higher number of microstates.

${ }^{10}$ While not being land-tied reduces the direct cost of agglomerating at the central marketplace, it does so for other equilibria as well. Lower costs can differentially increase payoffs at the central marketplace and increase the steepness of the basin of attraction.
} 
I have ruled out other mechanisms by design. But the game has multiple equilibria, so it is not entirely deterministic in its predictions and provides only probabilistic claims about a small set of equilibria being selected. I also isolate the effects of variety and land-tied on agglomeration, but whether or not my hypotheses hold is an empirical question, so I perform a laboratory experiment.

\section{Experimental Design}

I design a laboratory experiment to test the model described in the theory section. In the experiment, 6 participants are assigned an initial location and 12 units of a particular good as shown in Figure 1. Participants only make the location and good choices for the first stage of the game, with the computer automatically computing the second stage equilibrium based on choices in the first stage. Specifically, each individual simultaneously chooses to bring one good to one location and then a Walrasian equilibrium is computed based on the number and variety of goods brought to that location. Each participants makes these choices for 32 periods, having their endowments reset before they begin the next period. Participants' home locations are also reset in some sessions but update to the last location chosen in other sessions.

\subsection{Treatments}

Twelve experimental sessions were conducted two at a time within the same room. I started one of the parallel sessions with 2 goods and the other with 3 goods. After half of the periods have completed, the locations are reset and the number of goods changes, either increasing from $2 \rightarrow 3$ or decreasing from $3 \rightarrow 2$ depending on the initial treatment in the session. I refer to the periods before the switch as occuring under the first time block and the periods after as occuring under the second time block. The first six parallel sessions treated home locations as not land-tied $\triangle_{t+1}=\ell_{t}$, while the next six parallel sessions treated homes as land-tied, $\triangle_{t+1}=\varsigma_{0}$. The entire design is shown in Table 3 . There are two land-tied blocks (land-tied, not), each with six sessions where the number of goods goes from $2 \rightarrow 3$ and six sessions goes from $3 \rightarrow 2$ and each session having six individuals.

Table 3: Experimental Design: Sessions $\times$ Individuals

\begin{tabular}{lcc}
\hline \hline & \multicolumn{2}{c}{ \# Goods } \\
& $2 \rightarrow 3$ & $3 \rightarrow 2$ \\
\hline Land-Tied & $6 \times 6$ & $6 \times 6$ \\
Not Land-Tied & $6 \times 6$ & $6 \times 6$ \\
\hline
\end{tabular}

\subsection{Hypotheses}

All sessions are used to test the first and second hypotheses that individuals agglomerate to reap the gains from trade and that once formed they will re-emerge after shocks. The resetting of locations and different number of goods at the halfway point provides the shock. There is also within session and across session variation in the number of goods, providing a clear test of the strong and weak forms of third hypothesis that variety incentivizes agglomeration. The experiment also provides an across-session test on the effect 
of being land-tied. While this was important to Smith (1776) it was not precisely pinned down by my theory, so the experiment provides much insight into the land-tied effect.

\subsection{Procedure}

The experiment took place at Chapman University in April 2018. The experimental participants were undergraduate students who sat in 2 rows of individual cubicles connected to my repurposed $\mathrm{R}+$ Shiny software hosted on Amazon Web Server. For each session, I recruited 12 subjects to the lab at random from the subject pool of the Economic Science Institute Laboratory at Chapman University. No subject had any experience in a prior spatial coordination experiment, and no subject participated in our experiment more than once. Each session lasted 1 hour and subjects earned $\$ 18$ on average based on the lab-standard $\$ 7$ show up fee plus two random periods earnings. ${ }^{11}$ Individuals were not allowed to communicate with one another but every individual had an identical summary map that displays the location of all goods and average payoffs in the previous period. Each individual also had a private information tab that displays their individual history and a set of sliders to help simulate counterfactuals. Before beginning the experiment, the subjects received paper copies of the instructions. The interface and instructions are shown in Appendix Figure B.1. I first orally presented the instructions to the subjects alongside a tutorial period before a self-paced practice period. The experiment began when no subjects had additional questions. The subjects then made choices for 16 periods, after which I announced the number of goods had changed and locations were reset. The subjects then made choices for another 16 periods.

\subsection{Identifying Agglomeration}

My experiment rules out other factors that cause agglomeration by design, but the experiment also allows me to cleanly identify agglomeration. I am able to address three important measurement issues in the empirical literature: 1) the modifiable unit area problem - at what spatial scale to measure agglomeration 2) the definition problem - how to empirically calculate agglomeration 3) the Greenland problem - how do the calculations depend on the curvature of the earth. I discuss how my experiment addresses each of these issues in turn.

For the modifiable unit area problem, scholars either perform the same analysis at different scales or aggregates data to large pixels which presumably "internalizes agglomeration externalities" (Henderson et al. 2018). Although there often remains some uncertainty about what the right scale is, I can analyze location choices at the smallest scale but also aggregate data to the level that exactly captures the relevant area for agglomeration. But even without the modifiable unit area problem, the question still remains as to how to empirically calculate agglomeration.

While there are different many different ways to calculate agglomeration (Kominers 2008), a common class of definitions are built around population levels or densities. This can be problematic because many of those measures do not capture how those densities change over space but instead capture other factors like population growth. ${ }^{12}$ In my experiment, there is no variation in the population levels, so factors like

\footnotetext{
${ }^{11}$ Each individual was payed at the end of the experiment based on one $U_{i}^{2}$ selected for each of the two within-session treatments that were converted to dollars at an exchange rate of $\$ 1 / 4$.

${ }^{12} \mathrm{~A}$ good example of the difference is illustrated by seperately comparing three populations along a line. The first popu-
} 
population growth will not be affecting any of my measurements. But to address the definition issue, I will perform mutliple analyses, including visualizing the raw population distributions and regression analysis using an aggregate index of population concentration. But even when using the right measure at the right scale, the Greenland problem would still exist.

The Greenland problem refers to the misrepresentation of sizes on maps that are not equal-area projections (i.e. how Greenland appears to be the size of Africa when using the Mercator projection). For certain questions this is not a major statistical issue, but is crucial for measuring agglomeration. For example, using different sized bins to count up and compare a population uniformly distributed along a continuum will create a systematic bias towards finding higher counts in larger sized bins. While it is not known how the Greenland problem, the definition problem, and the modifiable unit area problem all interact to affect the measurement of agglomeration, I am able to rule out all of these issues. ${ }^{13}$ Furthermore, by evenly distributing the initial population, agglomeration will be easy to identify from visualizations before constructing any metrics.

\section{Empirics}

\subsection{Choices of Locations}

The results of the experiment are summarized in Figure 3. The top figure shows variation over time while the bottom figures show variation over space. In particular, Panel A shows the average number of people per populated cell within each treatment over time. The bottom left figure (Panel B) shows the average population distribution over Periods 13,14,15,16 for each session (grouped by treatment), with larger populations having darker colors. The bottom right figure (Panel C) shows the average population distribution over Periods 29,30,31,32 for the same sessions under the different treatments. For example, the session on the top left of the 'Land-Tied, 2 Goods' treatment has about 3 individuals at the cell in the 1st-row 3rd-column, 2 individuals at the cell in the 2nd-row 1st-column, and less than that at other locations, on average over periods 13-16. Over periods 29-32, that same session is shown in the top left of the 'Land-Tied, 3 Goods' treatment, and has about 5 individuals in the 3rd-row 3rd-column and 1 individual or less at other locations on average. A time-series of maps for all sessions is shown in Appendix Figures 6 and 7.

Figure 3 suggests a number of important findings. First, Panels B and C provide evidence for the geographical notion of "place and space". First and foremost, individuals form central marketplaces in support of Hypothesis 1. Looking at Periods 13-16 and Periods 29-32, the proportion of sessions that had a spatial coverage of only 1 cell was $1 / 3$. This is far more than predicted by the distribution of microstates in Table 2 or that the six individuals agglomerated at any of the cells by pure chance, $\sum_{15}(1 / 15)^{6}$. But individuals also return to the "place" (the cell where everyone was trading) not the "space" (everywhere

lation is normally distributed along a line; the second population is also normally distributed along the long but with a larger population at every point, and the third population is normally distributed along a line but with a larger variance than the first. When comparing the second and third populations to the first, only the second is oviously less agglomerated.

${ }^{13}$ For example, my empirics contrast with the $R^{2}$ measure used by Henderson et al. (2018). The comparison of OLS regresssions with trade variables vs agriculture variables in predicting the brightness of pixels has the three problems outlined. But it also does not rule out non-dichotomous explanations - such as one by Bairoch (1988) who argued agriculture affects trade in fostering urbanization or Smith (1776) who argued "without the assistance of some artificers, indeed, the cultivation of land cannot be carried on but with great inconveniency and continual interruption." 
else), in support of Hypothesis 2. I formalize this result by calculating the number of sessions that had the same maximum population cell at the end of period 32 and period 16. More than half of the sessions $(13 / 24)$ had the same maximum population location, over half of which $(7 / 24)$ were not at the central cell. These proportions are far larger than the proportion predicted by pure chance that any of the 15 cells would be selected as the "place" twice, $\Sigma_{15}(1 / 15)^{2}$. I perform a regression analysis to formalize other findings, but these calculations and Figure 3 provide sufficient support for the following

Finding 1: Central marketplaces often emerge.

Finding 2: Central marketplaces often reemerge at the same location after shocks. 
Figure 3: Evolution of Population Concentration

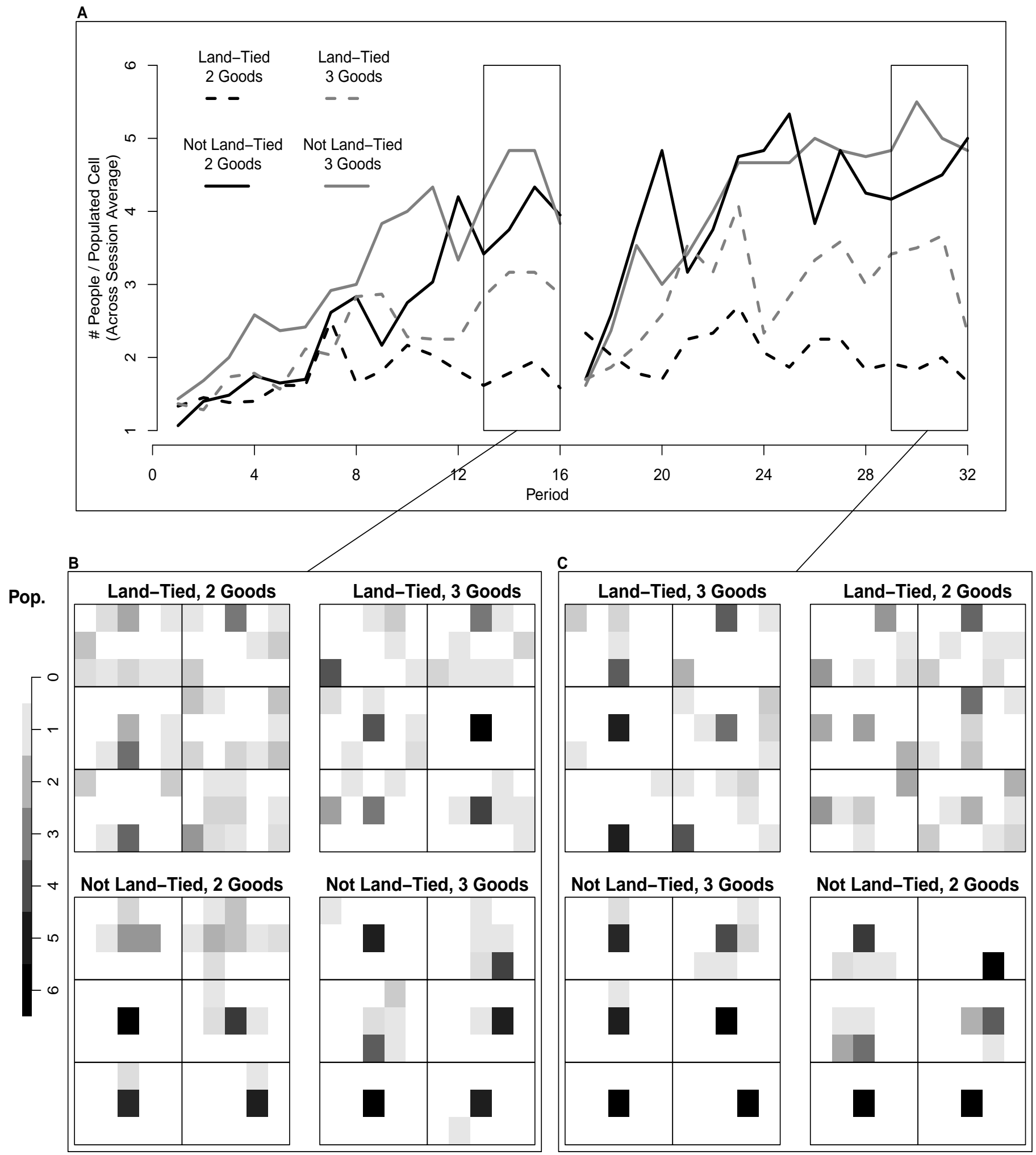

*Panel A: average number of people per populated cell within each treatment over time

*Panel B: average number of people per cell over periods 13-16 within each session, sessions grouped by treatment *Panel C: average number of people per cell over periods 29-32 within each session, sessions grouped by treatment 


\subsection{Regression Analysis}

I measure population concentration using a Hirschman Herfindahl Index at the grid level; HHI $=\sum_{\ell}\left(n_{\ell}\right)^{2}$ where $n_{\ell}$ is the share of the population in cell $\ell$. I then test my hypotheses with two OLS regressions of $E\left[H H I_{g, t}\right]=\alpha+\beta$ Three Goods $_{g, t}$ where the unit of observation is grid $g$ at time period $t$. As in Panel A of Figure 3, I restrict the data to the last 4 periods of each time block for each session. The first regression also includes session fixed effects, while the second includes fixed effects for whether it was the first or second time blocks and other covariates. Table 4 shows the results of those regressions, which is followed by discussion.

Table 4: Population Concentration

\begin{tabular}{lcc}
\hline \hline & \multicolumn{2}{c}{ HHI } \\
\cline { 2 - 3 } & $(1)$ & $(2)$ \\
\hline Three Goods & $0.181^{* * *}$ & $0.256^{* * *}$ \\
& $(0.045)$ & $(0.049)$ \\
Not Land-Tied & & $0.381^{* * *}$ \\
& & $(0.074)$ \\
Three Goods x Not Land-Tied & & $-0.149^{*}$ \\
& & $(0.074)$ \\
\hline F.E. & & TimeBlock \\
Observations & Session & 192 \\
$\mathrm{R}^{2}$ & 192 & 0.444 \\
\hline \hline
\end{tabular}

Notes: Unit of observation is a grid $\mathrm{g}$ at time $\mathrm{t}$ for each session over each of last 4 periods in a time block. Dependant variable is population concentration as measured by HHI. Standard errors are clustered on Session ID and $(* \mathrm{p}<0.05 ; * * \mathrm{p}<0.01 ; * * * \mathrm{p}<0.001)$.

The first column looks within sessions over time periods, and shows a positive coefficient for 'Three Goods'. This means that a population becomes more spatially concentrated when that economy has more variety. The second column looks across sessions within a time period and shows the coefficient for 'Three Goods' remains positive before and after adding the interaction term from 'Three Goods $\mathrm{x}$ Not Land-Tied' (statistically different from 0 with $p<10 \%$ under a Wald chi-square test). This means that economies with more variety are more concentrated regardless of whether they are land-tied, and thus supports the strong version of Hypothesis 3. The second column also shows a positive coefficient for 'Not Land Tied' which means economies that are not land-tied have more concentrated populations, supporting Hypothesis 4. A negative interaction effect is also shown, which the theory made no predictions about. This means the effect of variety is smaller in economies that are not land-tied. While the standard errors are larger for the interaction effect, a visual inspection of population per populated cell (Panel A, Figure 3) also supports this relationship and further suggests that being land-tied impedes the initial formation of central marketplaces in economies with fewer goods. As a whole, these data support the following findings 
Finding 3: Central marketplaces are more likely to emerge with a larger variety of goods in the economy. Finding 4: Central marketplaces are less likely to emerge when individuals are land tied.

Finding 5: Being land-tied magnifies the effect of variety on agglomeration.

While Table 4 follows much of the empirical work by using an aggregate index or level, I also exploit the non aggregated data to measure agglomeration as a dynamic spatial process. Specifically, I estimate a diffusion coefficient in Appendix Section A.4. These results provide a complementary interpretation of Findings 2 and 3; sessions with that were land-tied or had 2 goods were more diffusive than sessions had 3 goods or were not land-tied. Both the HHI and diffusion results are consistent with the costbenefit analysis in the theory: when the gains from trade are higher or the costs of trading are lower, agglomeration is more common.

\subsection{Zipf Distributed Aggregates}

Economic geographers have long been fascinated by, and providing explanations for, the linear relationship between the $\log ($ size $)$ and the $\log (\operatorname{rank}($ size $)$ ) of cities, in particular with a slope close to 1 (Auerbach 1913; Henderson 1974; Gabaix 1999; Eeckhout 2004; Dittmar 2011; Gabaix 2016). Many have also theorized about general underlying mechanisms for such linear rank-size relationships - i.e. birth/death dynamics (Simon 1955) and divisions into groups (Adamic 2011). Those theories cannot explain why I find that statistical rank-size relationship in my experiment. Figure 4 shows that summing all individuals over all time periods for each location generates a Zipf distributed population. ${ }^{14}$

Figure 4: Zipf Distributed Aggregations

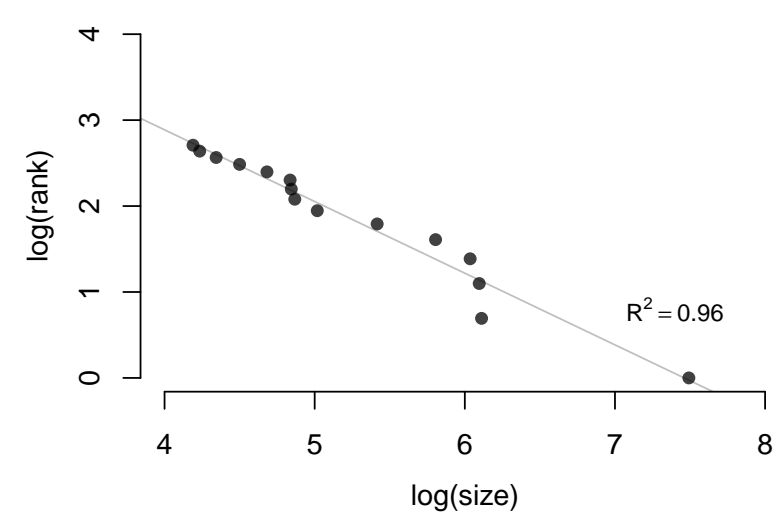

This is an important finding because my experimental results match both the historical descriptions of cities emerging from trade as well as the statistical description of cities. Since the location choices in my experiment are based purely on the gains from trade, the data support the following finding

Finding 6: The aggregate distribution of individual location choices to trade is approximately Zipf.

\footnotetext{
${ }^{14}$ Appendix Section A.6 provides more statistical details about why the sum of heterogeneous location choices creates a fat-tailed population distribution.
} 


\subsection{Choices of Goods}

There is also an important distinction between micro and macro patterns of the goods chosen by individuals. Table 5 shows the average amounts of each good brought each individual in the treatment. The last column shows the average number of periods each individual changed which good they brought, out of the 16 periods. These results show that individuals anti-coordinated their goods on average, but were frequently switching who brought which ones.

Table 5: Individual Good Choices

\begin{tabular}{rrrrrr}
\hline \hline & & Quantity $\boldsymbol{~ Q u a n t i t y ~} \bullet$ Quantity $\Delta$ & \#Switches \\
\hline Not Land-Tied & 2 Goods & 10.9 & 10.9 & & 5.8 \\
Land-Tied 2 Goods & 8.8 & 8.7 & & 5.1 \\
Not Land-Tied 3 Goods & 11.1 & 11.0 & 11.0 & 8.6 \\
Land-Tied & 3 Goods & 8.3 & 8.3 & 8.4 & 8.0 \\
\hline
\end{tabular}

The model predicted that the strategic uncertainty at the individual level should incentivize a central marketplace being selected. The reason is because central marketplaces are resilient to large deviations from equilibrium behaviour. So the first finding that central marketplaces often emerge is in part explained by the following finding.

Finding 7: Choices of goods were individually chaotic but still anti-coordinated on average.

Although individual payoffs increase from anti-coordination on goods, it was a very difficult problem for individuals to figure out exactly who should bring what. Thaler, Sunstein, and Balz (2012) are right that "Humans make mistakes. A well designed system expects its users to err and is as forgiving as possible." Those groups that endogenously formed central marketplaces were able to take advantage of the average anti-coordination and reaped the gains from trade.

\subsection{Welfare and Normative Outlook}

Many scholars argue decentralized individuals fail to coordinate on desireable equilibria (Van Huyck, Battalio, and Beil 1990; Ochs 1990; Cooper 1999) or that agglomerations suffer from some type of market failure (Quinzii and Thisse 1990; Fujita and Thisse 2013b; Behrens and Robert-Nicoud 2015; Gaubert 2018) - coordination failure in particular. My theoretical calculations in Section 2.3 also suggest central marketplaces are not optimal. However, the large number of equilibria and the even larger number of states of the world suggests finding a better state is a more appropriate criterion for success than a theoretically ideal equilibrium. ${ }^{15}$ Along these lines, I compare the payoffs actually acheived to both the maximum equilibrium-payoff in the long-run (what I specify as 0 transportation costs) and a randomwalk counterfactual. The long run payoff is 36 in the 3 good economy, and 24 for the 2 good economy. The simulated random walk yeilds an average payoff of about 10 for either 2 or 3 good economies. ${ }^{16}$

\footnotetext{
${ }^{15}$ Cassady (1974) states "as time went on, regularly scheduled congregations of would be traders at some central point came into existence. There were obviously inherent advantages in the regular gathering of those wishing to trade, rather than relying haphazardly attempting to find one another in order to effect an exchange of goods".

${ }^{16}$ The random walk was performed for each treatment. There were 100 simulation, each for 32 periods, where each individuals location in the next period is a multinoulli random variable with step-wise probability for locations that cost less
} 
Figure 5 shows a time series of average individual payoffs, as well as both counterfactuals as thin dotted lines.

Figure 5: Payoffs Over Time

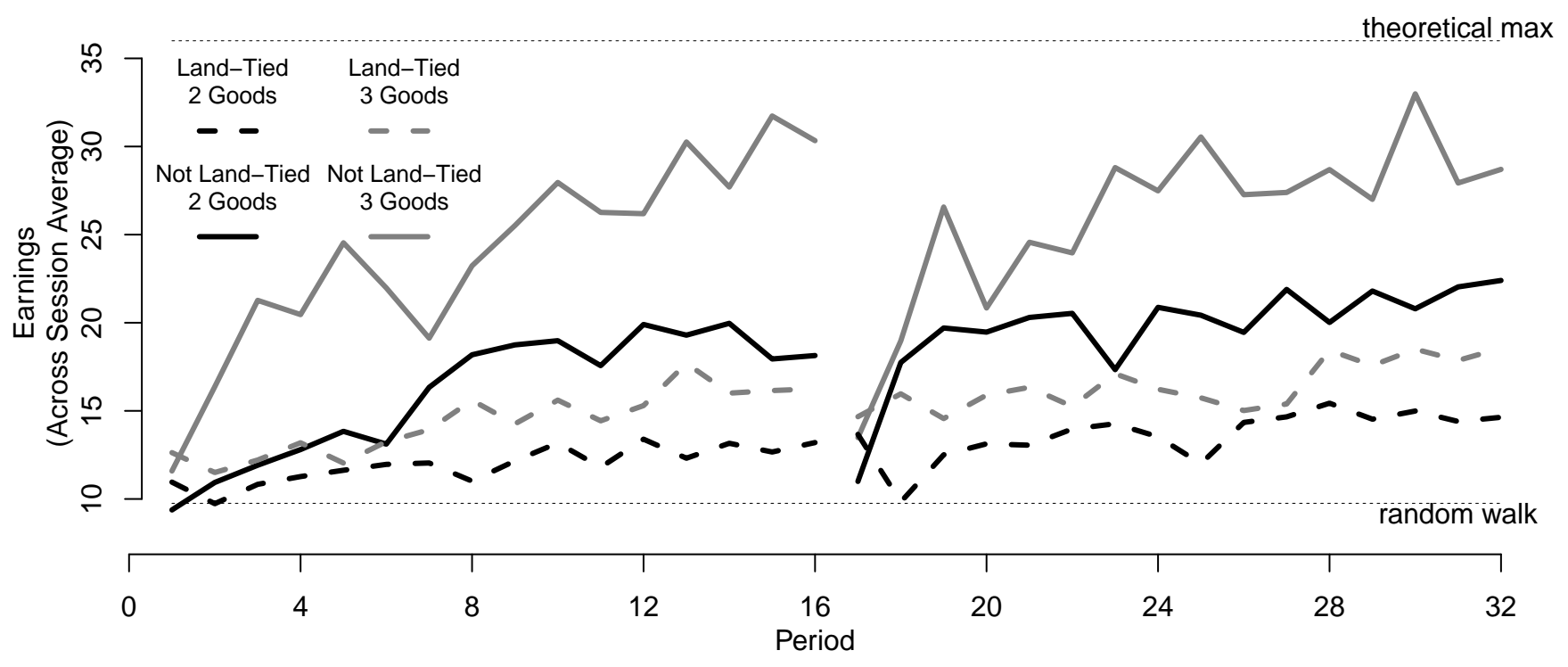

Only when individuals are not land-tied do they get close to the long run maximum, but payoffs are higher than the random-walk counterfactual in all cases (and much higher in some cases). However, it is problematic that these theoretical calculations depend heavily on the model parameters, as different theoretical ideal points could be constructed which could paint very different pictures. So I avoid this counterfactual-counterfactual problem and compare the payoffs actually observed when central marketplaces were and were not formed. Table 5 shows that individuals changed goods frequently and Figure 3 shows that sessions without central marketplaces were scattered irregularly. Thus these data suggest that sessions without central marketplaces were not coordinated at all in comparson to those with marketplaces. I then perform a regression analysis that compares locations within and across sessions. Those regressions show that locations with larger numbers of traders (over all periods) had higher average payoffs. So although sessions which formed central marketplaces did not reach theoretical maximim utility, they did perform much better than sessions which did not. ${ }^{17}$ This evidence supports the following finding

Finding 8: Marketplaces emerge as a spatial-coordination device which improves the welfare of traders.

Marketplaces bring people together who have certain goods, and want certain others, at the right place and time. In a world with a complex strategy space and a vast number of non-coordinating possibilities this is a market-success not a market-failure. This normative outlook is important because the gains from simplifying and stabilizing the exchange process are not included in any standard welfare calculation and the economist is generally uncertain about a models' parameters or even which games are being played. So whether or not "our cities become uneconomically large" (Hotelling 1929) depends on whether it is competition or coordination that brings us together, amongst other things. ${ }^{18}$

than 6 endowment units and 0 probability elsewhere.

${ }^{17}$ Moreover, if there are behavioral constraints or environmental uncertainties, then the central marketplace might actually
be the best we can hope for.

${ }^{18}$ In my experiment, individuals with the same good have choosen the same location for reasons that have nothing to 


\section{Conclusion}

I further the historical narrative of marketplaces with the modern microeconomic toolkit. Specifically, I develop a pure-exchange location-coordination game that isolates the effects of economic variety and land-tied residences. Although there are multiple equilibria, the model predicts evolutionary forces should lead traders to agglomerate. I then test the model in a controlled virtual environment. Repeat observations show that marketplaces emerge for dispersed traders to agglomerate and exchange, and with greater tendency with a larger variety of goods. I argue that marketplaces spatially coordinate trade, which helps Robinson, Crusoe, and many others to self-organize into markets and cities. Overall, I argue that such Smithian Agglomeration is an important component of economic geography.

Taken together, this game and experiment provide a starting point for further research on isolating the different agglomeration mechanisms. While this experiment focussed on one causal chain, much future work remains. In particular, it remains to incorporate the reverse direction of causality (such as the role of agglomerations in encouraging specialization), to integrate different mechanisms (such as city defenses), to compare the magnitudes of different forces (such as spatial competition vs. spatial coordination), and to expand to larger and more general settings (such as exchange and agglomeration at nodes in an internet web). The microeconomics of spatially coordinated trade helps shed new light on marketplaces and cities. For example, helping to answer open questions by Roth (2018, address to the A.E.A.) about the role marketplaces in markets and which forces encourage or inhibit them. And the experimental method is an exciting frontier to isolate and test the formation mechanisms.

do with spatial-competition. Spatial-coordination, where producers and consumers co-locate where they expect to find each other, could plausibly be confounded with spatial-competition in other settings. 


\section{References}

Adamic, Lada (2011). “Complex Systems: Unzipping Zipf's Law”. In: Nature 474.7350, 164-165.

Algaze, G. (2009). "The Evidence for Trade". In: Ancient Mesopotamia at the Dawn of Civilization: The Evolution of an Urban Landscape. University of Chicago Press.

Allen, Treb and Dave Donaldson (2018). The Geography of Path Dependence. Working Paper.

Andersen, Helle Damgaard (1997). "The Archaeological Evidence for the Origin and Development of the Etruscan City in the 7th to 6th Centuries BC". In: Urbanization in the Mediterranean in the 9th to 6th Centuries BC. Ed. by Helle Damgaard Andersen et al. University of Chicago Press.

Anderson, Robert M, Glenn Ellison, and Drew Fudenberg (2010). "Location Choice in Two-Sided Markets with Indivisible Agents". In: Games and Economic Behavior 69.1, 2-23.

Auerbach, Felix (1913). "Das Gesetz der Bevölkerungskonzentration." In: Petermanns Geographische Mitteilungen 59, 74-76.

Bairoch, Paul (1988). Cities and Economic Development: From the Dawn of History to the Present. University of Chicago Press.

Bakker, Jan David et al. (July 2018). Of Mice and Merchants: Trade and Growth in the Iron Age. Working Paper 24825. National Bureau of Economic Research.

Banerjee, Simanti, Anthony M. Kwasnica, and James S. Shortle (2012). "Agglomeration Bonus in Small and Large Local Networks: A Laboratory Examination of Spatial Coordination”. In: Ecological Economics 84, 142-152.

Barjamovic, Gojko et al. (2017). Trade, Merchants, and the Lost Cities of the Bronze Age. Working Paper 23992. National Bureau of Economic Research.

Behrens, Kristian and Frédéric Robert-Nicoud (2015). "Agglomeration Theory with Heterogeneous Agents". In: Handbook of Regional and Urban Economics. Vol. 5. Elsevier, 171-245.

Boardman, John (1999). The Greeks Overseas: Their Early Colonies and Trade. 4th ed. Thames and Hudson.

Boschma, Ron and Koen Frenken (2018). "Evolutionary Economic Geography". In: The New Oxford Handbook of Economic Geography. Oxford University Press. Chap. 11.

Boschma, Ron and Ron Martin (2010). "The Aims and Scope of Evolutionary Economic Geography". In: The Handbook of Evolutionary Economic Geography. Edward Elgar Cheltenham, 3-39.

Boulding, Kenneth (1964). The Meaning of the Twentieth Century: The Great Transition. George Allen and Unwin.

Caillié, René (2013). Travels Through Central Africa to Timbuctoo: And Across the Great Desert, to Morocco, Performed in the Years 1824-1828. Cambridge University Press.

Casajus, A. (2001). Focal Points in Framed Games: Breaking the Symmetry. Springer Berlin Heidelberg.

Cassady, Ralph (1974). Exchange by Private Treaty. Bureau of Business Research, University of Texas at Austin.

Christaller, Walter (1933). Central Places in Southern Germany. Prentice-Hall.

Combes, Pierre-Philippe, Gilles Duranton, and Laurent Gobillon (2011). "The identification of agglomeration economies". In: Journal of Economic Geography 11.2, 253-266.

Cooper, Russell (1999). Coordination Games: Complementarities and Macroeconomics. Cambridge University Press.

Crawford, Vincent P. (1991). “An “evolutionary” interpretation of Van Huyck, Battalio, and Beil's experimental results on coordination”. In: Games and Economic Behavior 3.1, 25-59.

Crawford, Vincent P. and Hans Haller (1990). "Learning How to Cooperate: Optimal Play in Repeated Coordination Games". In: Econometrica 58.3, 571-595. 
Creekmore, A. and K.D. Fisher (2014). Making Ancient Cities: Space and Place in Early Urban Societies. Cambridge University Press.

Davis, Donald and David Weinstein (Dec. 2002). "Bones, Bombs, and Break Points: The Geography of Economic Activity". In: American Economic Review 92.5, 1269-1289.

De Palma, André and Yorgos Papageorgiou (2017). About the Origin of Cities. Working Paper. HAL.

Desmet, Klaus, Dávid Krisztián Nagy, and Esteban Rossi-Hansberg (2018). "The Geography of Development”. In: Journal of Political Economy 126.3, 903-983.

Dillian, Carolyn and Carolyn White (2009). Trade and Exchange: Archaeological Studies from History and Prehistory. Springer New York.

Dittmar, Jeremiah (2011). “Cities, Institutions, and Growth: The Emergence of Zipf's Law”. In: Institute for Advanced Study.

Earle, Timothy and Kristian Kristiansen (2010). Organizing Bronze Age Societies: The Mediterranean, Central Europe, and Scandanavia Compared. Cambridge University Press.

Eeckhout, Jan (Dec. 2004). “Gibrat's Law for (All) Cities”. In: American Economic Review 94.5, 1429_ 1451.

Ellison, Glenn (2000). "Basins of Attraction, Long-Run Stochastic Stability, and the Speed of Step-byStep Evolution”. In: The Review of Economic Studies 67.1, 17-45.

Fierro, Alfred (1998). Historical Dictionary of Paris. Scarecrow Press.

Fudenberg, Drew and Glenn Ellison (2003). “Knife-Edge or Plateau: When Do Market Models Tip?” In: Quarterly Journal of Economics 118, 1249-1278.

Fujita, Masahisa, Paul Krugman, and Anthony Venables (2001). The Spatial Economy: Cities, Regions, and International Trade. MIT Press.

Fujita, Masahisa and Jacques-François Thisse (2013a). "Back to von Thünen: The Emergence of Cities in a Spatial Economy”. In: Economics of Agglomeration: Cities, Industrial Location, and Globalization. Cambridge University Press. Chap. 10, 387-425.

- (2013b). Economics of Agglomeration: Cities, Industrial Location, and Globalization. Cambridge University Press.

Gabaix, Xavier (1999). “Zipf's Law for Cities: An Explanation”. In: The Quarterly Journal of Economics 114.3, 739-767.

- (Feb. 2016). "Power Laws in Economics: An Introduction”. In: Journal of Economic Perspectives 30.1, 185-206.

Gaubert, Cecile (Apr. 2018). Firm Sorting and Agglomeration. Working Paper 24478. National Bureau of Economic Research.

Gibbons, Stephen and Henry G. Overman (2012). “Mostly Pointless Spatial Econometrics?” In: Journal of Regional Science 52.2, 172-191.

Glaeser, Edward (June 2005). Urban Colossus: Why is New York America's Largest City? Working Paper 11398. National Bureau of Economic Research.

- (Dec. 2007). The Economics Approach to Cities. Working Paper 13696. National Bureau of Economic Research.

Henderson, Vernon (1974). “The Sizes and Types of Cities”. In: The American Economic Review 64.4, 640656.

Henderson, Vernon et al. (2018). "The Global Distribution of Economic Activity: Nature, History, and the Role of Trade". In: The Quarterly Journal of Economics 133.1, 357-406.

Hodder, Bramwell William (1965). "Some Comments on the Origins of Traditional Markets in Africa South of the Sahara". In: Transactions of the Institute of British Geographers, 97-105.

Hotelling, Harold (1929). "Stability in Competition”. In: The Economic Journal 39.153, 41-57. 
Ibáñez, Juan José et al. (2018). "The Emergence of the Neolithic in the Near East: A Protracted and Multi-Regional Model”. In: Quaternary International 470, 226-252.

Irmen, Andreas and Jacques-François Thisse (1998). "Competition in Multi-characteristics Spaces: Hotelling Was Almost Right”. In: Journal of Economic Theory 78.1, 76-102.

Isoni, Andrea et al. (2013). "Focal Points in Tacit Bargaining Problems: Experimental Evidence". In: European Economic Review 59, 167-188.

Kenoyer, Jonathan Mark (1997). "Trade and Technology of the Indus Valley: New Insights from Harappa, Pakistan". In: World Archaeology 29.2, 262-280.

Kenoyer, Jonathan Mark, T. Douglas Price, and James H. Burton (2013). “A New Approach to Tracking Connections between the Indus Valley and Mesopotamia: Initial Results of Strontium Isotope Analyses from Harappa and Ur". In: Journal of Archaeological Science 40.5, 2286-2297.

Khalidi, Lamya (2010). "Holocene Obsidian Exchange in the Red Sea Region". In: The Evolution of Human Populations in Arabia: Paleoenvironments, Prehistory and Genetics. Ed. by Michael D. Petraglia and Jeffrey I. Rose. Dordrecht: Springer Netherlands, 279-291.

Kheirabadi, M. (1991). Iranian Cities: Formation and Development. Syracuse University Press.

Kimbrough, Erik O., Vernon L. Smith, and Bart J. Wilson (June 2008). "Historical Property Rights, Sociality, and the Emergence of Impersonal Exchange in Long-Distance Trade”. In: American Economic Review 98.3, 1009-39.

Kimbrough, Erik O. and Bart J. Wilson (2011). "Geography and Social Networks in Nascent Distal Exchange". In: Journal of Institutional and Theoretical Economics JITE 167.3, 409-433.

Kogler, Dieter (2015). "Editorial: Evolutionary Economic Geography - Theoretical and Empirical Progress". In: Regional Studies 49.5, 705-711.

Kominers, Scott (2008). "Measuring Agglomeration". In: Harvard Urban and Social Economics Seminar. Citeseer.

Kramarz, F. (May 1996). "Dynamic focal Points in N-person Coordination Games". In: Theory and Decision 40.3, 277-313.

Krugman, Paul (1991). "Increasing Returns and Economic Geography”. In: Journal of Political Economy 99.3, 483-499.

- (1996). The Self Organizing Economy. Wiley.

Litina, Anastasia (Dec. 2016). "Natural Land Productivity, Cooperation and Comparative Development". In: Journal of Economic Growth 21.4, 351-408.

Mannion, Antoinette (2011). "The Growth of the Obsidian Exchange Network in the Near East". In: World History Encyclopedia. Ed. by Alfred Andrea. ABC-CLIO.

Mark, Samuel (1998). From Egypt to Mesopotamia: A Study of Predynastic Trade Routes. Texas A\&M University Press.

Marshall, Alfred (1920). Industry and Trade: A Study of Industrial Technique and Business Organization; And of their Influences on the Conditions of Various Classes and Nations. Macmillan.

Martin, Ron and Peter Sunley (2007). "Complexity Thinking and Evolutionary Economic Geography”. In: Journal of Economic Geography 7.5, 573-601.

- (2012). "Forms of Emergence and the Evolution of Economic Landscapes". In: Journal of Economic Behavior \& Organization 82.2, 338-351.

Mattingly, D. J. and M. Sterry (2013). "The First Towns in the Central Sahara”. In: Antiquity 87.336, 503518.

McGeough, Kevin (2011). "Regional Exchange Networks". In: World History Encyclopedia. Ed. by Alfred Andrea. ABC-CLIO. 
McIntosh, Jane (2011). "Iranian Caravans across the Zagros". In: World History Encyclopedia. Ed. by Alfred Andrea. ABC-CLIO.

Mehta, Judith, Chris Starmer, and Robert Sugden (1994). "The Nature of Salience: An Experimental Investigation of Pure Coordination Games". In: The American Economic Review 84.3, 658-673.

Michailidou, Anna and Incifer Banu Dogan (2008). "Trading in Prehistory and Protohistory: Perspectives from the Eastern Aegean and Beyond". In: Sailing in the Aegean: Readings on the Economy and Trade Routes. Ed. by Charikleia Papageorgiadou-Banis and Angeliki Giannikouri, 17-53.

Morris, Ian (1992). "The Early Polis as City and State". In: City and Country in the Ancient World. Ed. by J. Rich and A. Wallace-Hadrill. Routledge, 43-77.

Neary, Peter (2001). “Of Hype and Hyperbolas: Introducing the New Economic Geography”. In: Journal of Economic Literature 39.2, 536-561.

Ochs, Jack (1990). "The Coordination Problem in Decentralized Markets: An Experiment". In: The Quarterly Journal of Economics 105.2, 545-559.

Parker, Phillip (2012). The Great Trade Routes: A History of Cargoes and Commerce Over Land and Sea. Naval Institute Press.

Parkins, Helen and Christopher John Smith (1998). Trade, Traders and the Ancient City. Routledge.

Parkinson, William A., Dimitri Nakassis, and Michael L. Galaty (2013). "Crafts, Specialists, and Markets in Mycenaean Greece. Introduction”. In: American Journal of Archaeology 117.3, 413-422.

Quinzii, Martine and Jacques-François Thisse (1990). “On the Optimality of Central Places”. In: Econometrica 58.5, 1101-1119.

Romano, Dennis (2015). Markets and Marketplaces in Medieval Italy, C.1100 to C.1440. Yale University Press.

Romer, Paul (1994). "New Goods, Old Theory, and the Welfare Costs of Trade Restrictions". In: Journal of Development Economics 43.1, 5-38.

Roth, Alvin E. (July 2018). "Marketplaces, Markets, and Market Design”. In: American Economic Review 108.7, 1609-58.

Sandholm, W.H. (2010). Population Games and Evolutionary Dynamics. MIT Press.

Schallin, Ann-Louise (1997). "Urban Centres, Central Places and Nucleation in Greek Islands versus the Greek Mainlands". In: Urbanization in the Mediterranean in the 9th to 6th Centuries BC. Ed. by Helle Damgaard Andersen et al. University of Chicago Press.

Schelling, Thomas (2006). Micromotives and Macrobehavior. Revised Edition. W. W. Norton.

Simon, Herbert (1955). "On a Class of Skew Distribution Functions". In: Biometrika 42.3/4, 425-440.

Smith, Adam (1776). An Inquiry into the Nature and Causes of the Wealth of Nations. 6th ed. London: A. Millar.

Tabuchi, Takatoshi and Jacques-François Thisse (2011). “A New Economic Geography Model of Central Places". In: Journal of Urban Economics 69.2, 240-252.

Thaler, Richard H., Cass R. Sunstein, and John P Balz (Dec. 2012). "Choice Architecture”. In: The Behavioral Foundations of Public Policy. Ed. by Eldar Shafir. Princeton University Press. Chap. 25.

Van Huyck, John, Raymond Battalio, and Richard Beil (1990). "Tacit Coordination Games, Strategic Uncertainty, and Coordination Failure”. In: The American Economic Review 80.1, 234-248.

Wendling, Holger (2013). "Manching Reconsidered: New Perspectives on Settlement Dynamics and Urbanization in Iron Age Central Europe”. In: European Journal of Archaeology 16.3, 459-490. 


\section{A Appendix}

\section{A.1 Historical Narratives of Smithian Agglomeration}

Many archeologists describe an important role of trade in early urban formations. For prehistory, see (Ibáñez et al. 2018; Bakker et al. 2018; Wendling 2013; Kenoyer, Price, and Burton 2013; Parkinson, Nakassis, and Galaty 2013; Parker 2012; Mannion 2011; McIntosh 2011; McGeough 2011; Khalidi 2010; Earle and Kristiansen 2010; Dillian and White 2009; Michailidou and Dogan 2008; Algaze 2009; Mark 1998; Kenoyer 1997). For ancient history see (Morris 1992; Andersen 1997; Schallin 1997; Parkins and Smith 1998; Boardman 1999; Creekmore and Fisher 2014; Barjamovic et al. 2017). There is even some fragmentary literary evidence on the role of marketplaces, such as the epic of Gilgamesh noting people collecting at the marketplace of Uruk and the word 'agora' (described in Oeconomicus) translating to both 'gathering place' and 'marketplace'.

There is better evidence for the role of trade in early medieval cities. For example, Berlin, Cologne, Hamburg, Bruges, Bergen all rose with Hanseatic trade, and Amsterdam, Lisbon, Seville, and London with transatlantic trade. Many historic towns and city-centers in Europe contain or directly translate to 'Market' or 'marketplace' (i.e. Nordic Kaupang) and some cities were founded for trade (i.e. Viking Dublin). Paris evolved into a great city alongside numerous markets and fairs, with ancient origins where the Parissi tribes coalesced at intersecting rivers Marne, Seine and Oise (Fierro 1998). But similar narratives are told outside of Europe, and some even describe early populations concentrating at marketplaces (Hodder 1965; Kheirabadi 1991; Romano 2015). Caillié (1824) documents in his landmark expedition that "Timbuctoo, though one of the largest cities I have seen in Africa, possesses no other resource but its trade" and Mattingly and Sterry (2013) argued trade was responsible for initial town formation. Glaeser (2005) argues trade played the crucial role in the historical development of New York.

\section{A.2 Extensive-Marginal Utility for CES Preferences}

To formalize the extensive margins for CES preferences, drop transport-costs and note

$$
\Delta(n, \rho)=\frac{U_{i}^{2}(n)-U_{i}^{2}(n-1)}{U_{i}^{2}(n)}=\left[\frac{\sum_{g=1}^{n}\left(\frac{\overline{\Omega_{g}(n)}}{\overline{\Omega_{i}(n)}}\right)^{\rho}}{\sum_{g=1}^{n-1}\left(\frac{\overline{\Omega_{g}(n-1)}}{\overline{\Omega_{i}(n-1)}}\right)^{\rho}}\right]^{\frac{1-\rho}{\rho}}-1
$$

Assume that adding the new good does not change the ratios of equilibrium consumption; $\overline{\Omega_{g}(n)} / \overline{\Omega_{i}(n)}=$ $\overline{\Omega_{g}(n-1)} / \overline{\Omega_{i}(n-1)}$. Then

$$
\left(\frac{\overline{\Omega_{n}(n)}}{\overline{\Omega_{i}(n)}}\right)^{\rho}+\sum_{g=1}^{n-1}\left(\frac{\overline{\Omega_{g}(n)}}{\overline{\Omega_{i}(n)}}\right)^{\rho}>\sum_{g=1}^{n-1}\left(\overline{\frac{\bar{\Omega}_{g}(n-1)}{\overline{\Omega_{i}(n-1)}}}\right)^{\rho}
$$

Then dividing by the right hand side implies $\Delta(n, \rho)>0$. Also see that the strength of the incentive depends on $\rho ; \rho \rightarrow 1$ (perfect substitutes) $\Rightarrow \Delta(n, \rho) \rightarrow 0$. Note that the CES function amplifies the effect of $\rho$ since all goods are substitutes or complements to the new good by an equal degree. Also note that adding transportation costs modify the incentives to agglomerate by altering endowment ratios in a 
generally uncertain way, and by reducing one's endowment which disincentivizes agglomeration.

\section{A.3 Data Summary}

\section{A.3.1 Land-Tied Location Choices}

Figure $6 a$ shows a time-series of 6 population heatmaps for each treatment ( 2 or 3 goods). Each map corresponds to a session, showing the average number of individuals at each location over the previous 4 periods, with larger populations having darker colors. For example, the 'Period 4' bi-panel of maps shows the six sessions that each have 3 goods are shown on the left in two columns and three rows. The session on the top left of that panel has an average (over periods $1-4$ ) of about 2 individuals at the cell in the 1st-row 3rd-column, 2 individuals at the cell in the 2nd-row 2nd-column, and less than that at other locations. In the bi-panel for 'Period 8', that session is shown in the same relative position, now averaging about 3 individuals at the cell in the 1st-row 4th-column and 3 individuals in the 3rd-row 1st-column. Figure $6 b$ shows the time-series of population maps after the locations were reset and the number of goods were changed. Note that these maps avoid the cell-size issues of satelite images, such as latitude/longitude projections which introduce a systematic bias by counting up people in heterogeneously sized cells. 
Figure 6: Number of Players per Cell (4 Period Averages), Land Tied

(a) 1 st Half

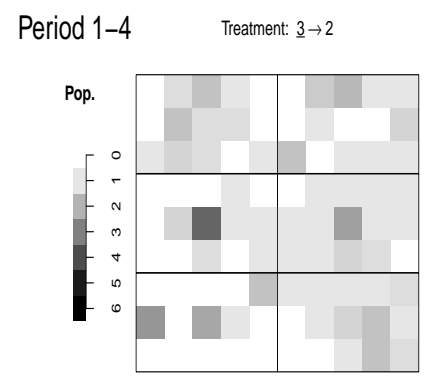

Period 5-8 Treatment: $3 \rightarrow 2$

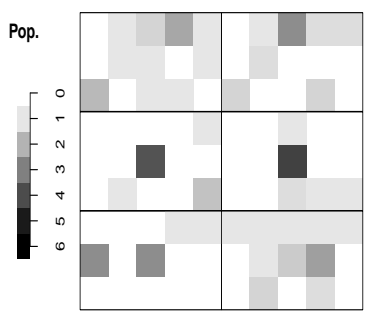

Period 9-12 Treatment: $\underline{3} \rightarrow 2$

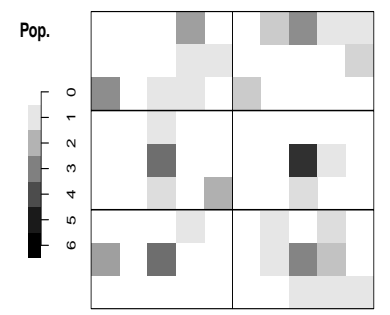

Period 13-16 Treatment: $\underline{3} \rightarrow 2$

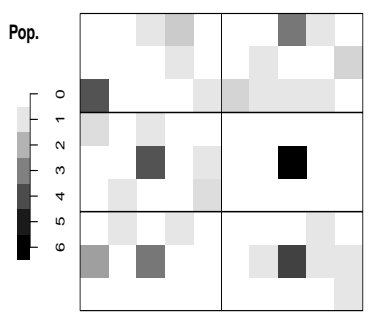

Treatment: $\underline{2} \rightarrow 3$

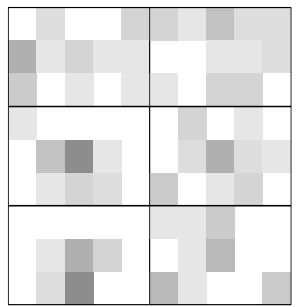

Treatment: $\underline{2} \rightarrow 3$

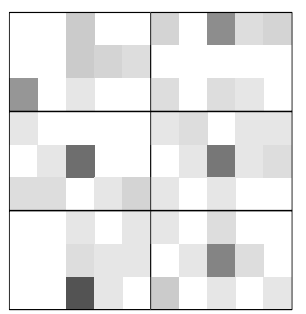

Treatment: $\underline{2} \rightarrow 3$

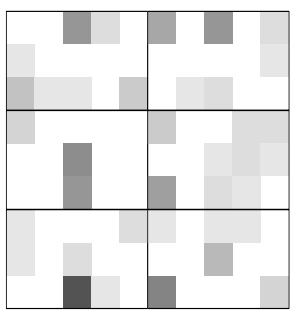

Treatment: $\underline{2} \rightarrow 3$

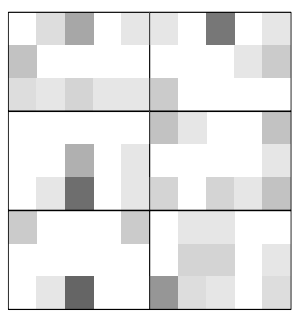

(b) 2nd Half

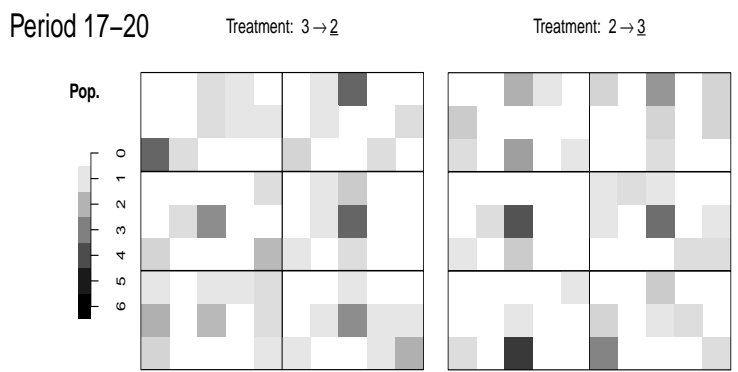

Period 21-24 Treatment: $3 \rightarrow \underline{\underline{2}}$

Treatment: $2 \rightarrow \underline{3}$
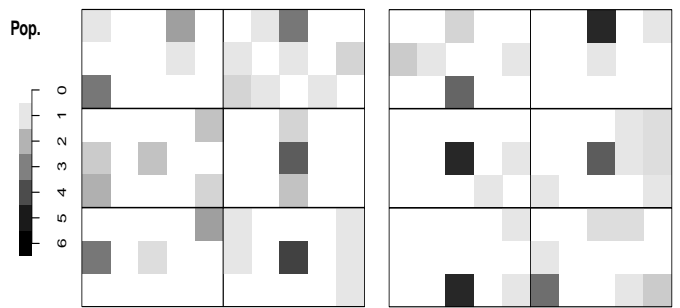

Period 25-28 Treatment: $3 \rightarrow \underline{2}$
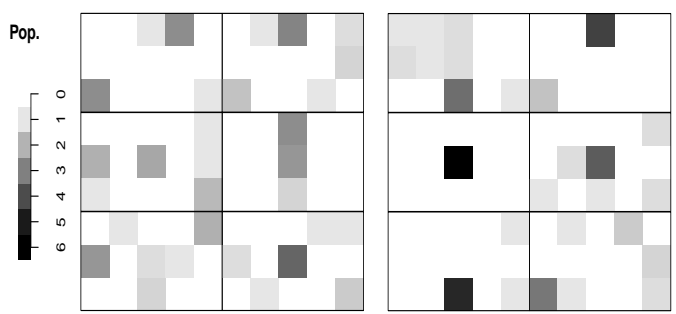

Period 29-32 Treatment: $3 \rightarrow \underline{2}$

Treatment: $2 \rightarrow \underline{3}$
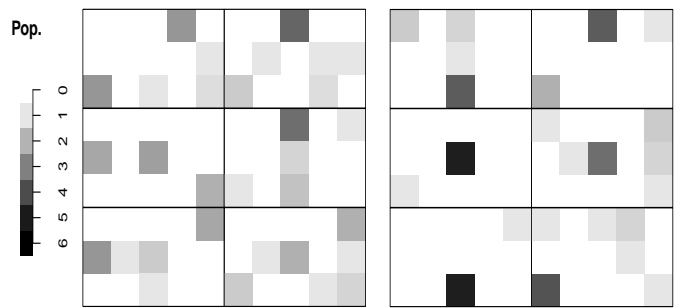

\section{A.3.2 Not Land-Tied Location Choices}

To test the effect of being Land-Tied, I let an individuals' home relocate with their location choices. Figure 7 shows how the location choices evolve, under both two and three good treatments, when individuals are not land-tied. There was a strong tendency for the initially dispersed population coalesces to a single point over time, even in two-good treatments. 
Figure 7: Number of Players per Cell (4 Period Averages), Not Land Tied

(a) 1 st Half

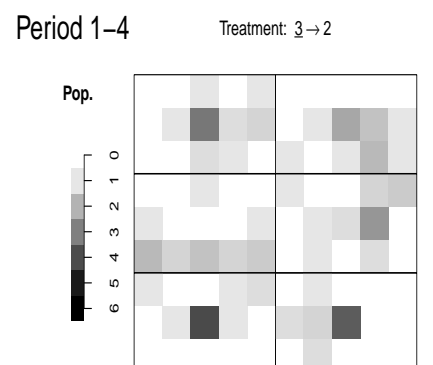

Period 5-8 Treatment: $3 \rightarrow 2$

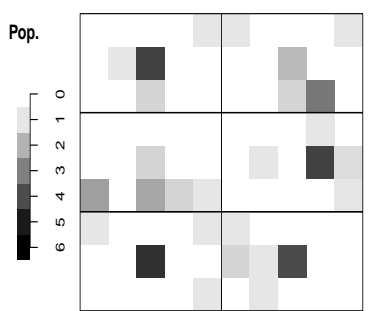

Period 9-12 Treatment: $3 \rightarrow 2$

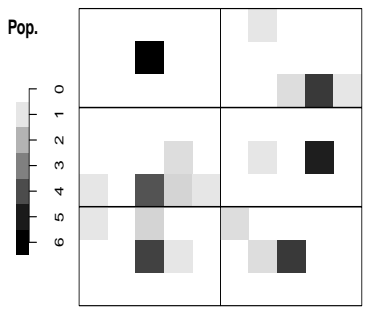

Period 13-16 Treatment: $\underline{3} \rightarrow 2$

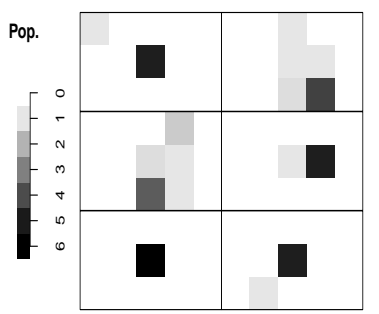

Treatment: $\underline{2} \rightarrow 3$

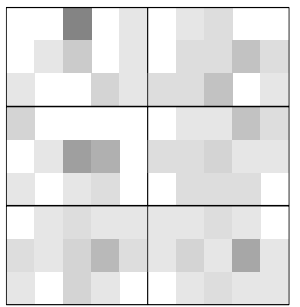

Treatment: $\underline{2} \rightarrow 3$

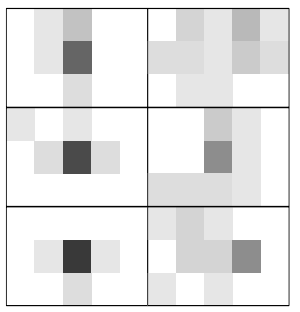

Treatment: $\underline{2} \rightarrow 3$

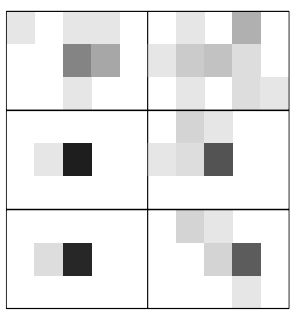

Treatment: $\underline{2} \rightarrow 3$

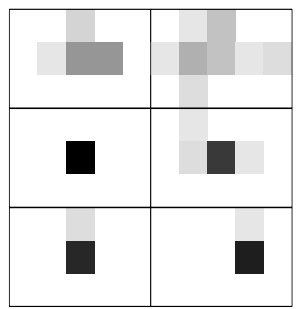

(b) 2nd Half

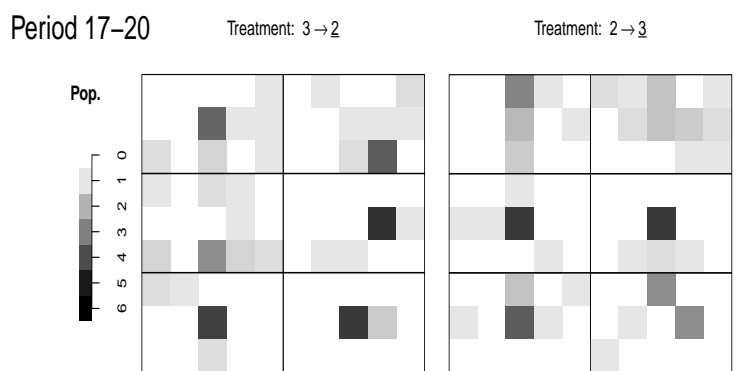

Period 21-24 Treatment: $3 \rightarrow \underline{\underline{2}}$

Treatment: $2 \rightarrow \underline{3}$
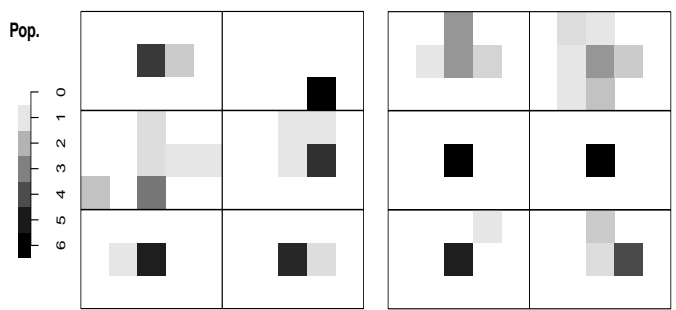

Period 25-28 Treatment: $3 \rightarrow \underline{\underline{2}}$

Treatment: $2 \rightarrow \underline{3}$
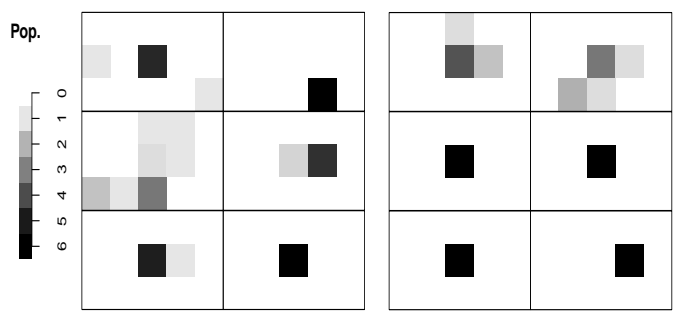

Period 29-32 Treatment: $3 \rightarrow \underline{2}$

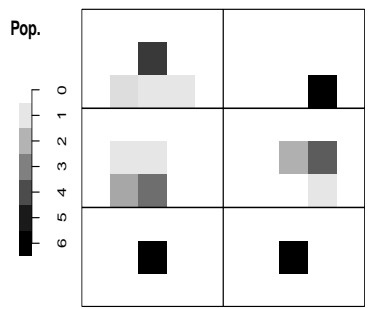

Treatment: $2 \rightarrow \underline{3}$

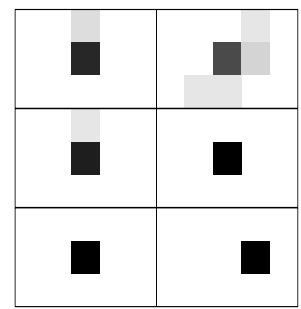

\section{A.4 Agglomeration as a Dynamic Spatial Process}

The diffusion coefficient differs from concentration indices by fully accounting for the spatial configuration, i.e. distinguishing bi-modal population-distributions that are close and far apart, and also differs from counts or densities which measure levels not changes over space and time. In words, the population in a cell this period is equals to the population there last period plus the net amount gained in the X-direction and Y-direction from last period. Specifically, I estimate the following first-order finite- 
difference approximation of the diffusion equation

$$
N(x, y, t)-N(x, y, t-1)=K\left[\begin{array}{r}
{[N(x-\Delta x, y, t-1)-N(x, y, t-1)]-[N(x, y, t-1)-N(x+\Delta x, y, t-1)]} \\
+[N(x, y-\Delta y, t-1)-N(x, y, t-1)]-[N(x, y, t-1)-N(x, y+\Delta y, t-1)]
\end{array}\right]
$$

where $N(x, y, t)$ is the population level at $(x, y, t), N(x-\Delta x, y, t)$ is the population level in the cell to the left, and $K$ is the coefficient of diffusion. While differencing over time and space will eliminate some level-terms (such as fixed effects), any errors in this process could plausibly have spatiotemporal autocorrelation. So I estimate $K$ by treating each session-block as a single large observation. Figure 8 groups each session-block by treatment, to show the distribution of coefficient estimates with the mean estimate shown as a vertical red line. Comparing the session-blocks shows that sessions with that were land-tied or had 2 goods were more diffusive.

Figure 8: Diffusion Coefficients
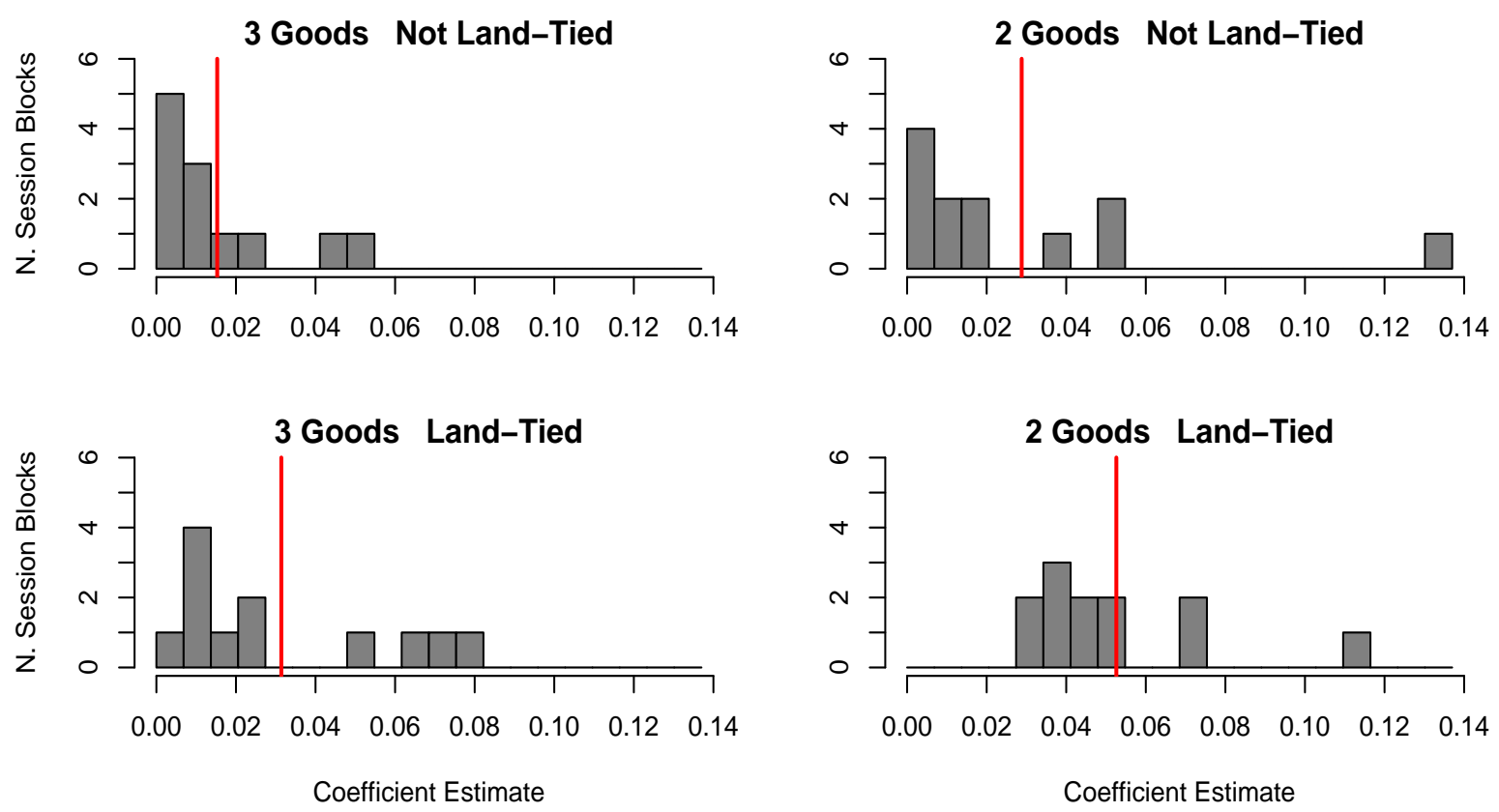

\section{A.5 Rank Size Distributions}

The size distribution function entirely characterizes the relationship between size and rank. First, note

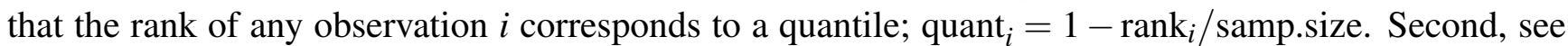
that size is associated with rank according to the quantile function; size $e_{i}=C D F^{-1}$ (quant $\left._{i}\right)=C D F^{-1}(1-$

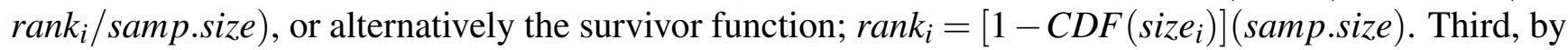
definition, a variable $x$ has a fat-tailed distribution if $1-C D F(x) \stackrel{x \rightarrow \infty}{\longrightarrow} x^{-\alpha}$. So finally, a particular $\alpha=1$ fat-tail distribution approximately yields the Zipf relationship: $\ln \left(\operatorname{rank}_{i}\right) \approx \ln (\operatorname{samp} . \operatorname{size})-\alpha \ln \left(\operatorname{size} e_{i}\right)$. Note that many non-negative distributins (i.e. those for sizes and counts) have a lot of probability mass in the right tail that could yield the approximate relationship. 


\section{A.6 Zipf Derivation}

Figure 4 shows the population aggregates follow a zipf distribution. Figure 9 shows a summary of each individuals frequency of choosing locations from most common, second-most common, ... to least common. I now show why Figure 9 leads to Figure 4.

Figure 9: Individual Relative Location Choices

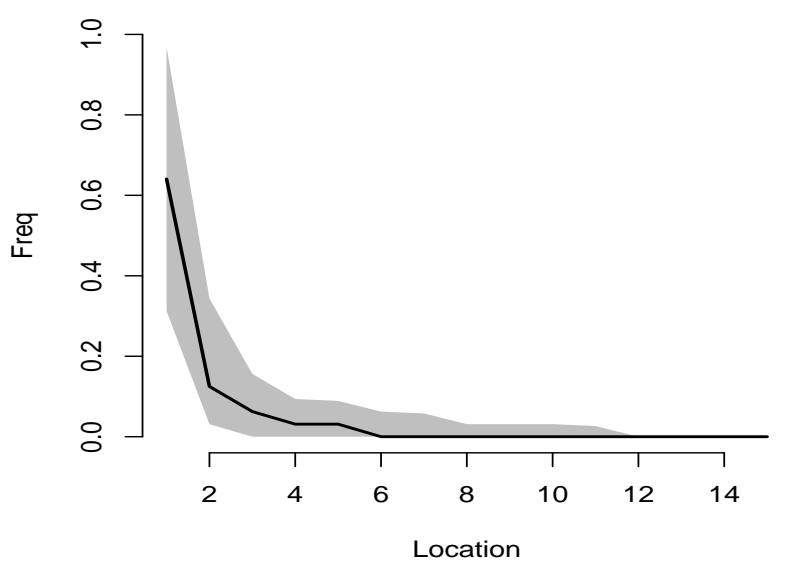

Assume individual $i$ choose location $k$ with probability $\sigma_{i}^{k}$; then $\ell_{i} \sim \operatorname{Multinoulli}\left(\sigma_{i}\right)$ Assume that all individuals have the same location ordering, with individual heterogeneity only in the probability magnitudes (i.e. as suggested in Figure 9). This means $\sigma_{i}=\sigma$ is randomly distributed, and the locationsum of $I$ people is a multinomial mixture distribution;

$$
s=\sum \ell_{i} \sim \operatorname{Multinomial}(I, \sigma)
$$

Note the expected population sums are $\bar{s}=E[s \mid \sigma, I]=I \sigma$, with the expected population size of a particular location $\bar{s}^{k} \in \bar{s}$ corresponding to the probability $\sigma^{k} \in \sigma$. Now assume that the distribution of expected sums conditioned on $\sigma$ are approximately exponential; $F\left(\bar{s}^{k} \mid \lambda\right)=1-\exp \left(-\lambda \bar{s}^{k}\right)$. Also assume that individual heterogeneity approximately takes the form $\lambda \sim \exp (\theta)$. Then substituting these exponential mixture weights into the survivor function, $\int_{0}^{\infty}\left[1-F\left(\bar{s}^{k} \mid \lambda\right)\right] f(\lambda) d \lambda$, implies that

$$
1-F\left(\bar{s}^{k}\right)=\left(1+\frac{\bar{s}^{k}}{\theta}\right)^{-1}
$$

For details on how the survivor function determines the rank-size relationship, see Appendix Section A.5. But this result means $\bar{s}^{k} \sim \log \log (\theta, 1)$, which is a fat-tailed distribution. In particular, since the lim $(1+$ $\left.\bar{s}^{k} / \theta\right)^{-1}-\left(\bar{s}^{k}\right)^{-1}=0$ as $\bar{s}^{k} \rightarrow \infty$, the expected population size distribution converges to a Pareto $(1)$ distribution. In line with empirical evidence, this limiting approximation also predicts population-counts are more likely to appear zipf when examining datasets with truncated populations. 


\section{B Experiment Instruction and Interface}

\section{Introduction}

This is an experiment on economic decision-making. If you read the instructions carefully and make good decisions, you can earn a considerable amount of money, which will be paid to you in CASH at the end of the experiment. Experimental decisions will involve Experimental Currency Units $(E C U)$ and will be converted to dollars at a rate of $4 E C U=\$ 1$ at the end of the experiment.

During the experiment you are not allowed to communicate with any other participant. You must also put away all materials unrelated to the experiment, including cell-phones, tablets, and pen-and-paper. If you do not follow these instructions you will be excluded from the experiment and paid only the show-up payment of $\$ 7$.

Before beginning the experiment, we will read through these instructions. Alongside the reading, we will do a tutorial showing you how the interface works. When these instructions say On my command, then wait for me to tell you what to do.

If you have any questions during the tutorial, quietly raise your hand, and I will call on you. If you have any questions during the experiment, quietly raise your hand, and I will answer them privately.

On my command, click "Initialize”.

\section{GamePlay Tutorial}

You have been given 12 units of either $\boldsymbol{\square}, \bullet$, or $\Delta$ and are located at $\triangle$ on the map. You should see your default endowment on the top left of the screen.

Your task is to decide where to locate. There are benefits from trade if people with different goods meet at the same location, but there are costs of moving locations. Note that every person will make these decisions simultaneously, so noone will know what any other person's decisions will be when making their own. Also note that not all goods will be available during some periods.

\subsection{Location Choice}

In each period of the experiment, you will click on a location on the map to move to. Every location has an $x$ and $y$ coordinate. You should see your default location $\triangle$ somewhere on the Location Choice Map. Every cell that you move away from $\triangle$ will cost you units of your endowment.

On my command, click somewhere else on the map one time.

Your total transportation costs to get there are shown below the $X$.

On my command, click your home location.

Your total transportation costs to get there are shown below the $X$. It costs you nothing to stay at home. 


\subsection{Endowment Choice}

In each period of the experiment, each of you will also choose which good to be endowed with. On my command, Click another good. On my command, Click your original good.

If you do not choose a different endowment, your endowment will be the same as last period.

\subsection{Earnings}

There are benefits to locating with others who can trade with you.

- If you and another player both choose the same location, and each player has the same good, then there won't be a trade and each will earn their endowment.

- If you and another player both choose the same location, and each player has a different good, then a trade will occur and your earnings will be higher than your endowment.

There can be more than two players at the same location. In general, your earnings increase when others bring more of a different good but not if they bring the same good as you.

On my command, click the "Earnings" tab.

You can see exactly what your earnings could be under different combinations by moving the sliders around. These sliders represent the quantity of different goods that you and other traders bring to a location.

On my command, put 9 units supplied of My Good, by Me.

- If you are endowed with $\boldsymbol{\square}$, then this means you brought $9 \square$.

- If you are endowed with $\bullet$, then this means you brought $9 \bullet$

- If you are endowed with $\Delta$, then this means you brought $9 \Delta$.

On my command, put 0 units supplied of My Good, by Others

- If you are endowed with $\mathbf{\square}$, then this means others brought $0 \mathbf{m}$.

- If you are endowed with $\bullet$, then this means others brought $0 \bullet$

- If you are endowed with $\Delta$, then this means others brought $0 \Delta$.

On my command, put 11 units supplied of Different Good \#1, by Others

- If you are endowed with $\boldsymbol{\square}$, then this means others brought either $11 \bullet$ or $11 \Delta$.

- If you are endowed with $\bullet$, then this means others brought either $11 \square$ or $11 \Delta$.

- If you are endowed with $\Delta$, then this means others brought either $11 \square$ or $11 \bullet$ 
On my command, put 0 units supplied of Different Good \#2, by Others You can see your Earnings would be 19.

- If you bring $9 \boldsymbol{m}$, then you earn 19 when noone else brings $\boldsymbol{\square}$ and other people bring either $11 \bullet$ or $11 \Delta$

- If you bring $9 \bullet$, then you earn 19 when noone else brings $\bullet$ and other people bring either 11 or $11 \Delta$

- If you bring $9 \Delta$, then you earn 19 when noone else brings $\Delta$ and other people bring either $11 \bullet$ or 11

On my command, Now put 10 units supplied of Different Good \#2, by Others You can see your Earnings would be 28 .

- If you bring $9 \mathbf{\square}$, then you earn 28 when noone else brings $\boldsymbol{\square}$ and other people bring either $(11 \bullet$ and $10 \Delta)$ or $(10 \bullet$ and $11 \triangleleft)$

- If you bring $9 \bullet$, then you earn 28 when noone else brings $\bullet$ and other people bring either (11 and $10 \Delta)$ or (10 and $11 \Delta)$

- If you bring $9 \boldsymbol{\Delta}$, then you earn 28 when noone else brings $\Delta$ and other people bring either $(11 \bullet$ and $10 \bullet)$ or $(10 \bullet$ and 11

On my command, increase the quantity supplied of My Good, By Others. See that this decreases your payoffs. Note that since there are only 5 other players, each with 12 units, the sum-total of all goods provided by others must be less than 60 . If you try to simulate more than that, you will get an error message.

Everyone take two minutes to play around with the sliders and understand your payoffs.

Are there any questions about how the simulator works?

Beside these sliders are a table. This table shows your previous location choices, the good you supplied, your earnings, and the period.

\subsection{History}

On my command, click the "History" tab.

There are 3 maps, each pertaining to a particular good, show a summary of everyones choices last period. Focus on the map of $\mathbf{m}$

Each location on this history map corresponds to a location on the location choice map. At each location, "Quant" shows the total quantity of $\boldsymbol{\square}$ brought by all players to that cell in the last period. Since this is the first period, there is no history, and all quantities are 0 . That will change as the game progresses; cells with more $\boldsymbol{m}$ in the last period will be colored darker blue. 
Also shown at each location are the average earnings of players who had $\boldsymbol{m}$. So if one player brought 9 — (3 units lost) and earned 38, and another brought 12 (0 units lost) and earned 50, then "Earn" would show $(50+38) / 2=44$.

The maps for $\bullet$ and $\Delta$ are read the same way. Are there any questions about how to read the maps?

\subsection{Period Timing}

Each period is timed, and lasts a total of 60 seconds. The amount of time left in the period is shown in the top right of the screen, and will update every 10 seconds.

You will have 55 seconds to make your choices. When the timer is up, you are moved to your chosen location. The computer will then exchange goods amongst all of the players at that location, and will calculate your earnings based on how much of each good everyone brought. These calculations are the same that are shown by the simulator. You will then see a pop-up for 5 seconds that summarizes your choices and your earnings. Your home will be moved the location you chose last period, you will get another 12 units, and the next period will begin.

Note that you can lock in your choices at any point before the timer is up by clicking the 'submit" button. If you don't click submit, then your location choice will be the last location clicked before the timer is up. If you do not click any locations, you will stay at your home location. Are there any questions about how the game will progress?

\section{Game Conclusion and Payment}

At the end of this experiment, a short post-game survey and a summary of your experiment payout will come up. Your in-game payment was calculated by randomly choosing your earnings from one period before a pause and one period after a pause and converting them from $E C U$ to $\$$. Your in-game payment is then added to your showup payment of $\$ 7$. Once you have submitted the survey, please remove your hands from the mice/keyboard and wait quietly. You will then soon be called up individually to receive your payment.

\section{Practice Round}

There will now be a live practice period where you can explore the interface on your own. Note that neither this period nor the tutorial can be chosen for payment. When this practice period is finished, please wait for further instruction.

On my command, make a location choice and click "Submit" to end the turial period and begin the practice round. 


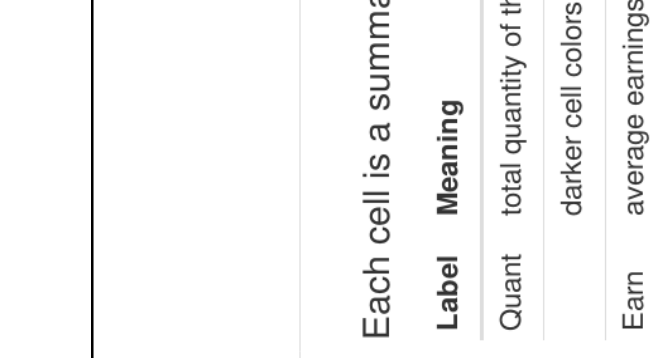

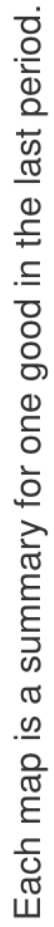

\begin{tabular}{|c|c|c|}
\hline 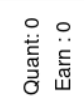 & 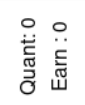 & 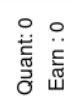 \\
\hline 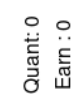 & 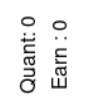 & 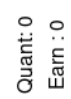 \\
\hline 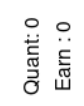 & 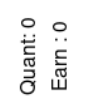 & 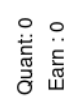 \\
\hline 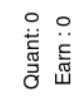 & 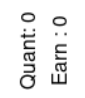 & 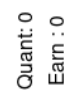 \\
\hline 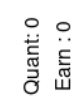 & 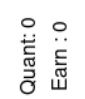 & 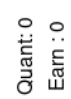 \\
\hline
\end{tabular}

\begin{tabular}{|c|c|c|}
\hline 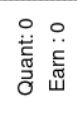 & 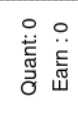 & 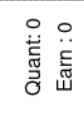 \\
\hline 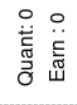 & 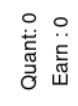 & 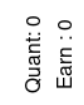 \\
\hline  & 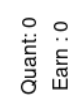 & 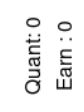 \\
\hline 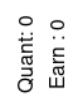 & 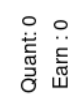 & 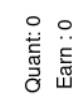 \\
\hline 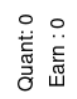 & 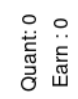 & 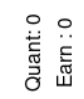 \\
\hline
\end{tabular}

$\bullet$
40
0
$\stackrel{2}{5}$
$\frac{7}{5}$

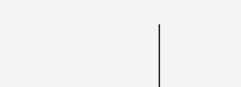

i

艺

高 음

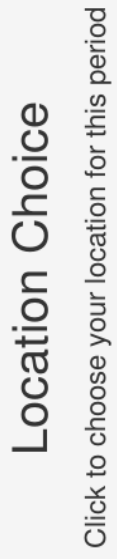

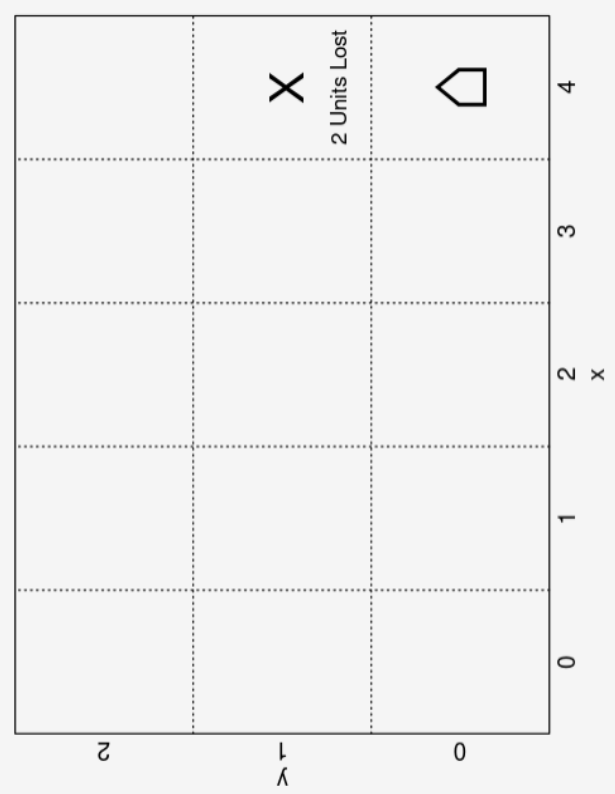

步

잉

ㅎํำ
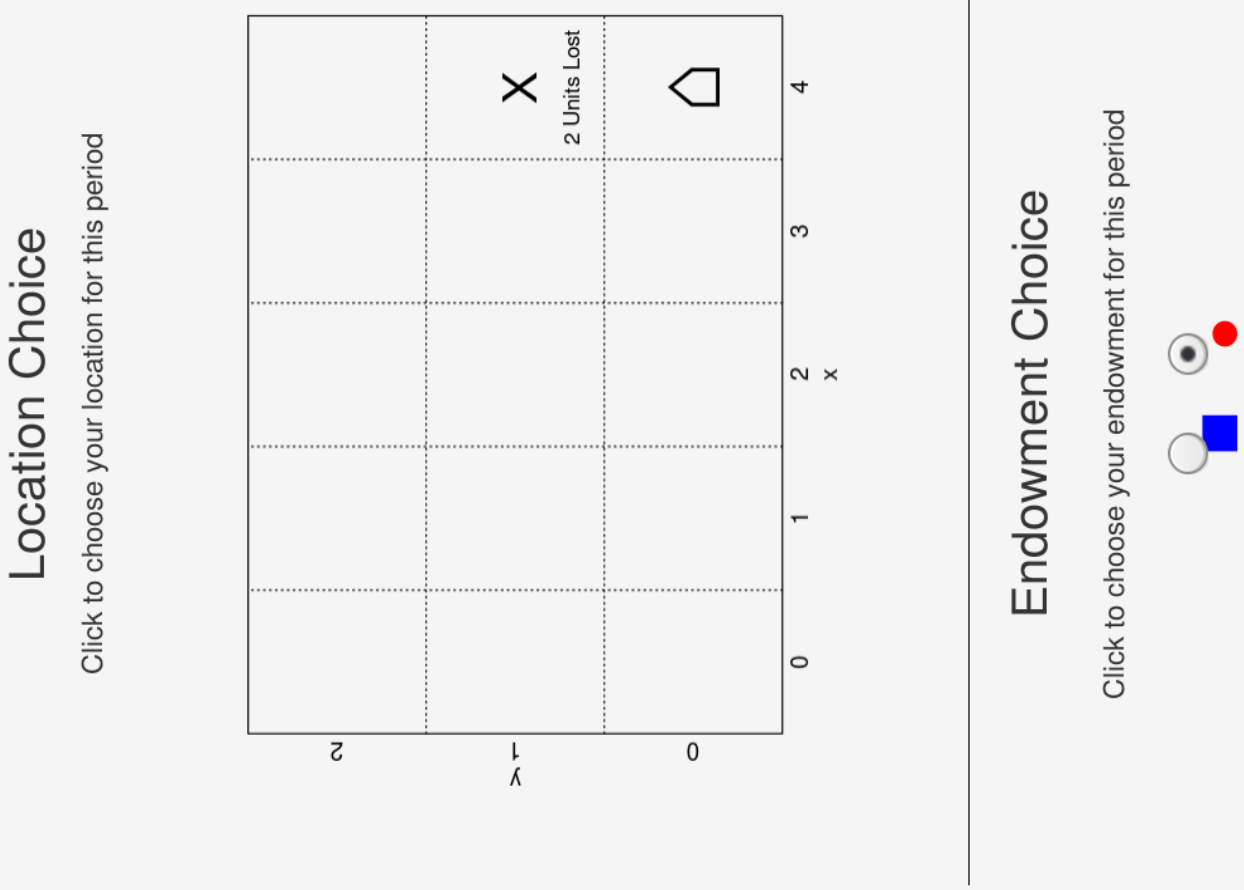

के 